\title{
A meta-analysis of the reproducibility of food frequency questionnaires in nutritional epidemiological studies
}

\author{
Qi Cui ${ }^{1 \dagger}$, Yang Xia ${ }^{1 \dagger}$, Qijun Wu', Qing Chang ${ }^{1}$, Kaijun Niu ${ }^{2^{*}}$ and Yuhong Zhao ${ }^{1^{*}}$ (D)
}

\begin{abstract}
Background: Reproducibility of FFQs measures the consistency of the same subject at different time points. We performed a meta-analysis to explore the reproducibility of FFQs and factors related to reproducibility of FFQs.

Methods and findings: A systematic literature review was performed before July 2020 using PubMed and Web of Science databases. Pooled intraclass and Spearman correlation coefficients (95\% confidence interval) were calculated to assess the reproducibility of FFQs. Subgroup analyses based on characteristics of study populations, FFQs, or study design were performed to investigate factors related to the reproducibility of FFQs. A total of 123 studies comprising 20,542 participants were eligible for the meta-analysis. The pooled crude intraclass correlation coefficients ranged from 0.499 to 0.803 and 0.499 to 0.723 for macronutrients and micronutrients, respectively. Energy-adjusted intraclass correlation coefficients ranged from 0.420 to 0.803 and 0.507 to 0.712 for macronutrients and micronutrients, respectively. The pooled crude and energy-adjusted Spearman correlation coefficients ranged from 0.548 to 0.851 and 0.441 to 0.793 , respectively, for macronutrients; and from 0.573 to 0.828 and 0.510 to 0.744 , respectively, for micronutrients. FFQs with more food items, 12 months as dietary recall interval (compared to less than 12 months), and a shorter time period between repeated FFQs resulted in superior FFQ reproducibility.
\end{abstract}

Conclusions: In conclusion, FFQs with correlation coefficients greater than 0.5 for most nutrients may be considered a reliable tool to measure dietary intake. To develop FFQs with higher reproducibility, the number of food items and dietary recall interval should be taken into consideration.

Keywords: FFQ, Food frequency questionnaire, Reproducibility, Meta-analysis, Macronutrients, micronutrients

\section{Introduction}

The FFQ is the most commonly used tool to assess individual usual dietary intake in nutritional epidemiological studies, especially for investigating the relationship between dietary and health outcomes $[1,2]$. FFQs allow researchers to rank subjects according to their dietary and

\footnotetext{
*Correspondence: nkj0809@gmail.com; niukaijun@tmu.edu.cn;

zhaoyuhong@sj-hospital.org

${ }^{\dagger}$ Qi Cui and Yang Xia contributed equally to this work.

${ }^{2}$ Present address: Nutritional Epidemiology Institute and School of Public

Health, Tianjin Medical University, Tianjin, China

1Present address: Department of Clinical Epidemiology, Shengjing Hospital of China Medical University, Shenyang, China
}

nutritional intake. Obtaining an accurate estimate of long-term habitual food intake is crucial [3], which is very important to better understand diet and associated diseases. However, assessment of nutritional habits is complex [4], and they are affected by real changes in regular dietary intake and random changes in FFQ $[5,6]$. FFQs allow covering a wider range of foods, including those consumed rarely, and can be administered once whereas to describe usual dietary habits with a reasonable reproducibility [7]. If the reproducibility is not maintained high enough, the dietary intakes of subjects measured at baseline would substantially misclassify their true exposure during the study period [8]. To

(c) The Author(s). 2021 Open Access This article is licensed under a Creative Commons Attribution 4.0 International License, which permits use, sharing, adaptation, distribution and reproduction in any medium or format, as long as you give appropriate credit to the original author(s) and the source, provide a link to the Creative Commons licence, and indicate if changes were made. The images or other third party material in this article are included in the article's Creative Commons licence, unless indicated otherwise in a credit line to the material. If material is not included in the article's Creative Commons licence and your intended use is not permitted by statutory regulation or exceeds the permitted use, you will need to obtain permission directly from the copyright holder. To view a copy of this licence, visit http://creativecommons.org/licenses/by/4.0/ The Creative Commons Public Domain Dedication waiver (http://creativecommons.org/publicdomain/zero/1.0/) applies to the data made available in this article, unless otherwise stated in a credit line to the data. 
enhance the interpretation of estimated diet-disease associations and to improve the translation of such associations into dietary recommendations, reproducibility analysis is required before applying FFQ to analyze dietary intake [9].

Reproducibility reflects reliability and refers to the similarity of the same method at different timepoints [10]. Reproducibility is generally assessed by administering the same FFQ twice to the same group of subjects and analyzing the association between the two responses [11]. Previous studies reported that the intervals between two FFQs varied from 1 week [12] to 2 years [13]. And true change in regular dietary intakes and random variation in response to the FFQ have been considered factors affecting the repeatability of FFQs [14], which result in reduced reproducibility of FFQs with long interval $[2,15]$. However, the two FFQs administered closely, respondents may remember and repeat their previous responses and result in high reproducibility [2].

Numerous studies have been devoted to assess the reproducibility of FFQs before applying FFQ to different populations. The Spearman and intraclass correlation coefficients (ICCs) to assess the reproducibility of 134item FFQs with approximately 6 months apart ranged from 0.46 to 0.79 and from 0.34 to 0.71 , respectively, for 25 nutrients in the Shanghai Diet and Health Study [16]. The reproducibility of another FFQ of 157 items with 3month interval used in the Food4Me study (a randomized controlled trial across seven European countries) has been reported to range from 0.62 to 0.89 [17]. Then, a repeatability study of an interview administered FFQ of 135 items in the Mexican Women's Bone Health Cohort Study found that the reproducibility coefficients range from 0.186 to 0.810 for energy-unadjusted data and 0.174 to 0.597 for energy-adjusted data [18]. However, the correlation coefficients of different nutrients evaluated in different studies are different, and a widely accepted reference value for the reproducibility of FFQs is currently lacking.

Furthermore, the characteristics of FFQs may affect their reproducibility. A previous study reported that the ICCs of an FFQ comprising 255 items ranged from 0.69 (fat) to 0.84 (vitamin A) in Moroccan adults [19]. A shorter FFQ assessing the average consumption of 57 food items was reported to have a reliability coefficient ranging from 0.56 to 0.70 [20]. Therefore, FFQ items may induce differences in reproducibility. A previous study suggested that the median (range) energy-adjusted Spearman correlation coefficients (SCCs) for 30 nutrients between two FFQ measurements was 0.24 (0.04$0.69)$ for men and $0.50(0.27-0.60)$ for women [21], suggesting that the reliability of FFQs differ between men and women. Moreover, differences in FFQ reproducibility may be caused by other factors [22], such as real changes in diet over time, individual differences in diet, and study design differences [22, 23]. However, there has been a paucity of studies comprehensively exploring the effects of these factors on the reproducibility of FFQs.

Although the reproducibility of FFQs has been evaluated in various studies, there has yet to be a comprehensive meta-analysis of the reproducibility studies and definition of reference ranges for reproducibility coefficients. Moreover, no study has systematically explored the factors related to the reproducibility of FFQs. Therefore, we conducted a meta-analysis to systematically assess the reproducibility of FFQs and to explore the factors related to the reproducibility of FFQs.

\section{Methods}

A systematic review was conducted according to the Preferred Reporting Items for Systematic Reviews and Meta-Analyses (PRISMA) guideline; the relevant checklist is provided in PRISMA Checklist.

\section{Literature search}

We conducted a comprehensive literature search for published studies from PubMed and Web of Science databases before July 2020 . The literature search was conducted by two independent researchers. The search strategy used employed the terms "FFQ OR food frequency questionnaire" AND "reproducibility OR repeatability OR reliability".

\section{Study identification and selection}

The potentially relevant articles were evaluated by two independent reviewers based on the inclusion. The original studies were obtained from the database. After removing duplicates, we screened the studies according to title and abstract. After reading the full texts, the eligible articles were obtained by exclusion criteria.

Articles were included if they met the following criteria: (1) FFQs were used to measure nutrient intake; (2) the age range of target healthy populations was between 8 and 86 years; (3) the study assessed the reproducibility of FFQs; (4) the study was published in English; and (5) the reproducibility of FFQs was measured with the intraclass correlation coefficient (ICC) and Pearson correlation coefficient or SCC.

The exclusion criteria were: (1) food intake was assessed using FFQs; (2) FFQs were used to assess a specific nutrient; (3) the target population was unhealthy people or specific populations, such as individuals who were overweight or malnourished; (4) the participants were less than 8 years old; (5) the article investigated diet-disease relationships; and (6) the full text was unavailable through web searches. 


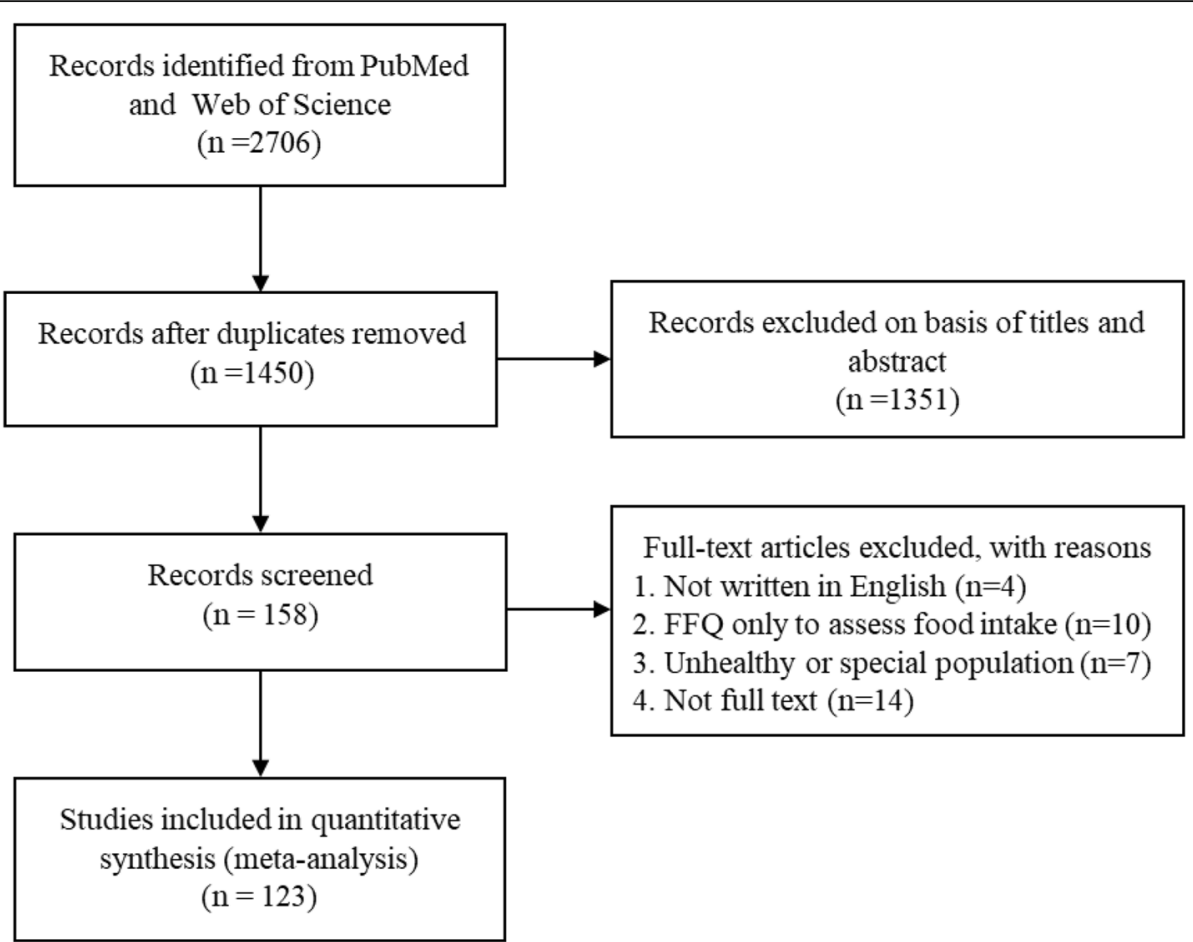

Fig. 1 Flowchart of the study selection process

\section{Data extraction}

Data were extracted from each study by independent reviewers. The extracted contents included the following, excluding authors and published years: (1) characteristics of participants including sample size, age, gender distribution, and region; (2) characteristics of FFQs including food items and dietary recall interval; (3) characteristics of study design including administration method and interval between two FFQs; and (4) statistics employed to assess reproducibility between repeated FFQs including ICC and Pearson correlation coefficient or SCC in relation to energy, macronutrients, and micronutrients (minerals and vitamins). Macronutrients included protein, fat, plant fat, animal fat, MUFA, PUFA, n-3 PUFA, n-6 PUFA, SFA, linoleic acid, linolenic acid, EPA, DHA, trans-fat, cholesterol, lipid, carbohydrate, sucrose, sugar, starch, fiber, soluble fiber, insoluble fiber, and alcohol. Minerals included selenium (Se), magnesium (Mg), calcium $(\mathrm{Ca})$, iron $(\mathrm{Fe})$, iodine $(\mathrm{I})$; zinc $(\mathrm{Zn})$, copper $(\mathrm{Cu})$, potassium $(\mathrm{K})$, phosphorus $(\mathrm{P})$, sodium $(\mathrm{Na})$, and manganese $(\mathrm{Mn})$. Vitamins included vitamin $\mathrm{A}$, retinol, carotene, $\beta$-carotene, vitamin $C$, vitamin $D$, vitamin $E$, vitamin $K$, thiamin, riboflavin, niacin, vitamin $B 6$, folate and vitamin B12.

\section{Meta-analysis}

The pooled correlation coefficients were calculated based on the ICC and SCC values obtained from each article. We converted Pearson correlation coefficients into SCCs if the latter were lacking. Fisher's transformation was used to convert each correlation coefficient to an approximately normally distributed $z$-value. The standard error of $\mathrm{z}$ was calculated. After appropriate conversion, random effects meta-analyses were used to combine data. The heterogeneity of the z-values among studies was determined by calculating the inconsistency index $\left(\mathrm{I}^{2}\right) . \mathrm{I}^{2}$ greater than $50 \%$ indicated the presence of heterogeneity. $\mathrm{z}$-values were converted using inverse Fisher's transformation to obtain correlation coefficients and $95 \%$ CIs to account for results. Sensitivity analysis was performed to explore the when to further explore the source of heterogeneity.

Studies were stratified according to the following characteristics: (1) population characteristics including age ( $<18$ years, $18-50$ years, and $>50$ years), gender, and region; (2) characteristics of the reproducibility studies including sample size ( $\leq 112$ and $>112$, the cutoff point was the median of sample size) and time interval between repeated FFQs ( $\leq 6$ months and $>6$ months, the cutoff point was the median of time interval); and (3) characteristics of FFQ design including FFQ items ( $\leq$ 120 and $>120$, the cutoff point was the median of item), dietary recall interval ( $\geq 12$ months and $<12$ months), administration mode (interviewer-administered or selfadministered). All statistical analyses were performed using Stata Software (Version 11.0 Stata, College Station, 
TX, USA). A $P$-value less than 0.05 was considered statistically significant.

\section{Results}

Literature search and study selection

The flow chart of the study selection is shown in Fig. 1. We identified 2706 original studies from the database. After removing 1256 duplicates, 159 articles met the inclusion criteria according to title and abstract screening. After reading the full texts, 35 articles were excluded according to exclusion criteria. In total, we obtained 123 articles based on the procedure described above.

\section{Study characteristics}

An overview of the retrieved studies assessing the reproducibility of FFQs is presented in Table 1 (detail information shown in Supplemental Table 1). Of the 123 articles included [4, 10-13, 15-18, 20, 21, 23-134], two articles analyzed differences in different age groups [50, 113], and five articles assessed the differences in reproducibility according to time intervals between repeated FFQs $[39,91,96,113,134]$. The extracted information on characteristics of the included studies is summarized in Table 1 (detail information shown in Supplemental Table 1). The median sample size per study was 112 (range: 14-1981), with a total of 20,542 participants. The age range of participants was between 8 and 86 years. The studies were divided into three groups according to age: adult ( $18-50$ years), elderly ( $>50$ years) and adolescent ( $<18$ years); these comprised 77,33 , and 15 studies, respectively. For studies with a wide participant age range covering cutoff point, the mean age

Table 1 Summary of the characteristics of the included studies ${ }^{\text {a }}$

\begin{tabular}{|c|c|c|c|c|}
\hline & Overall & Adult & Old & Adolescent \\
\hline Range of age (years) & $8-86$ & $18-50$ & $>50$ & $8-17$ \\
\hline Number of studies & 124 & 78 & 33 & 15 \\
\hline \multicolumn{5}{|l|}{ Population characteristics } \\
\hline Total number & 20,830 & 11,336 & 7897 & 1597 \\
\hline Sample size & $112(14-1981)$ & $102(20-1623)$ & $158(14-1981)$ & $101(48-185)$ \\
\hline \multicolumn{5}{|l|}{ Distribution of gender } \\
\hline \multicolumn{5}{|l|}{ Region } \\
\hline Africa & $6(4.88)$ & $5(6.49)$ & $0(0)$ & $1(6.67)$ \\
\hline Oceania & $8(6.50)$ & $5(6.49)$ & $2(6.07)$ & $1(6.67)$ \\
\hline Asia & $37(30.08)$ & $22(28.57)$ & $11(33.33)$ & $4(26.67)$ \\
\hline Europe & $35(28.46)$ & $22(28.57)$ & $10(30.30)$ & $4(26.67)$ \\
\hline America & $37(30.08)$ & $23(29.87)$ & $10(30.30)$ & $5(33.33)$ \\
\hline \multicolumn{5}{|l|}{ FFQ design characteristics } \\
\hline \multicolumn{5}{|l|}{ Items of FFQ } \\
\hline$\geq 120$ & $61(49.59)$ & $41(53.25)$ & $15(45.45)$ & $5(33.33)$ \\
\hline$<120$ & $62(50.41)$ & $36(46.75)$ & $18(54.55)$ & $10(66.67)$ \\
\hline \multicolumn{5}{|l|}{ Dietary recall intervals } \\
\hline$\geq$ Previous 12 months & $80(65.04)$ & $50(64.94)$ & $28(84.85)$ & $4(26.67)$ \\
\hline$<$ Previous 12 months & $33(26.83)$ & $20(25.97)$ & $3(9.09)$ & $10(66.67)$ \\
\hline Not available & $10(8.13)$ & $7(9.09)$ & $2(6.06)$ & $1(6.667)$ \\
\hline \multicolumn{5}{|c|}{ Characteristics of the reproducibility studies } \\
\hline \multicolumn{5}{|l|}{ Administration mode of FFQ } \\
\hline Interview-administered & $44(35.77)$ & $29(37.66)$ & $12(36.36)$ & $4(26.67)$ \\
\hline Self-administered & $63(51.22)$ & $36(46.75)$ & $19(57.58)$ & $9(60.00)$ \\
\hline Not available & $16(13.01)$ & $12(15.59)$ & $2(6.06)$ & $2(13.33)$ \\
\hline \multicolumn{5}{|l|}{ Intervals between FFQs } \\
\hline$<6$ months & $63(51.22)$ & $45(58.44)$ & $8(24.24)$ & $12(80.00)$ \\
\hline$\geq 6$ months & $55(44.72)$ & $29(37.66)$ & $23(69.70)$ & $3(20,00)$ \\
\hline Both intervals & $5(4.06)$ & $3(3.90)$ & $2(6.06)$ & $0(0)$ \\
\hline
\end{tabular}

${ }^{\mathrm{a}}$ Values are $\mathrm{N}(\%)$ or median (range) 
reported in articles was used as the grouping criterion first. In addition, the median age was used to group population if the mean age was not available. For FFQ characteristics, the median number of FFQ items was 120. The number of studies that required participants to recall food intake for more or less than 12 months was 80 and 33, respectively. Of these studies, 44 were interview-administered, 63 were self-administered, and 16 were not available. Time intervals between FFQs varied considerably (from 1 week to 2.7 years), and studies were classified as less than 6 months $(n=63)$ or more than 6 months $(n=55)$.

\section{Correlation coefficients for energy and macronutrients}

As shown in Table 2, crude ICCs for reproducibility ranged from 0.499 for starch to 0.803 for alcohol (median: 0.667). All values for energy and macronutrients exceeded 0.5. After adjusting for energy, the range of
ICC was between 0.420 ( $\mathrm{n}-3$ PUFA) and 0.803 (alcohol) with a median value of 0.630 . Energy-adjusted ICCs of most nutrients exceeded 0.5 except those for n-3 PUFA, trans-fat, and soluble fiber. For SCCs, all pooled crude values ranged from 0.548 (plant fat) to 0.851 (alcohol) with a median value of 0.637 , and energy-adjusted values ranged from 0.441 (n-6 PUFA) to 0.793 (alcohol) with a median value of 0.580 . Most values were decreased after adjusting for energy, except those for lipid and plant fat. All pooled crude SCCs exceeded 0.5; energy-adjusted values exceeded 0.5 except those for $n-3$ PUFA and n- 6 PUFA. Heterogeneity was high for energy and most nutrients in crude and energy-adjusted ICCs and SCCs $\left(\mathrm{I}^{2}>50 \%\right)$.

\section{Correlation coefficients for micronutrients}

Table 3 depicts the reproducibility of the FFQ measurements in terms of pooled ICCs and SCCs for micronutrients. For vitamins, the pooled crude and energy-

Table 2 Pooled effect estimates and heterogeneity of the correlation coefficients for the reproducibility of FFQ for energy and macronutrient $^{a}$

\begin{tabular}{|c|c|c|c|c|c|c|c|c|c|c|c|c|}
\hline \multirow[t]{3}{*}{ Nutrient } & \multicolumn{6}{|c|}{ ICC } & \multicolumn{6}{|l|}{ SCC } \\
\hline & \multicolumn{3}{|c|}{ Crude } & \multicolumn{3}{|c|}{ Energy-adjusted } & \multicolumn{3}{|c|}{ Crude } & \multicolumn{3}{|c|}{ Energy-adjusted } \\
\hline & $\bar{N}$ & ICC $(95 \% \mathrm{CI})$ & $1^{2}$ & $\bar{N}$ & ICC $(95 \% \mathrm{CI})$ & $1^{2}$ & $\bar{N}$ & ICC $(95 \% \mathrm{Cl})$ & $I^{2}$ & $\mathrm{~N}$ & ICC $(95 \% \mathrm{Cl})$ & $I^{2}$ \\
\hline Energy & 61 & $0.709(0.652,0.758)$ & 96.3 & N/A & N/A & $\mathrm{N} / \mathrm{A}$ & 106 & $0.649(0.624,0.673)$ & 84.6 & N/A & N/A & N/A \\
\hline rotein & 63 & $0.648(0.612,0.682)$ & 88.3 & 25 & $0.600(0.546,0.650)$ & 80.4 & 106 & $0.609(0.584,0.632)$ & 80.6 & 64 & $0.558(0.521,0.593)$ & 80.5 \\
\hline Fat & 55 & $0.644(0.599,0.684)$ & 91.1 & 19 & $0.564(0.483,0.634)$ & 86.3 & 104 & $0.623(0.599,0.644)$ & 78.4 & 56 & $0.555(0.516,0.593)$ & 81.3 \\
\hline ant fat & 5 & $0.572(0.461,0.665)$ & 60.0 & 2 & $0.615(0.489,0.715)$ & 0 & 6 & $0.548(0.468,0.619)$ & 62.0 & 2 & $0.580(0.214,0.803)$ & 90.6 \\
\hline Animal fat & 2 & $0.696(0.462,0.839)$ & 74.7 & 2 & $0.725(0.585,0.822)$ & 46.4 & 4 & $0.693(0.661,0.722)$ & 0 & 2 & $0.575(0.513,0.630)$ & 0 \\
\hline IUFA & 4 & $0.641(0.60$ & 80.9 & 18 & 0.63 & 83.7 & 50 & $0.612(0.5$ & 68.0 & 31 & 0.5 & 1.3 \\
\hline UUFA & 45 & $0.641(0.575,0.699)$ & 94.6 & 45 & $0.573(0.488,0.646)$ & 85.5 & 57 & $0.595(0.566,0.623)$ & 73.4 & 31 & $0.521(0.466,0.572)$ & 79.4 \\
\hline n-3 PUFA & 2 & $0.703(0.657,0.745)$ & 63.1 & 1 & $0.420(0.187,0.607)$ & N/A & 6 & $0.619(0.573,0.661)$ & 59.8 & 5 & $0.469(0.402,0.532)$ & 36.9 \\
\hline n-6 PUFA & 2 & $0.727(0$ & 61.3 & 1 & 0.510 & N/A & 6 & 0.594 & 18.3 & 5 & 0.4 & 57.4 \\
\hline SFA & 49 & $0.687(0.612,0.749)$ & 96.6 & 19 & $0.639(0.564,0.704)$ & 86.4 & 65 & $0.626(0.598,0.651)$ & 76.6 & 37 & $0.567(0.520,0.610)$ & 81.6 \\
\hline noleic acid & 5 & $0.666(0.491,0.790)$ & 93.3 & 3 & $0.685(0.591,0.760)$ & 71.0 & 9 & $0.615(0.552,0.670)$ & 80.6 & 9 & $0.577(0.487,0.653)$ & 86.3 \\
\hline Linolenic acid & 4 & $0.658(0.498,0.775)$ & 88.9 & 2 & $0.630(0.527,0.714)$ & 47.8 & 3 & $0.684(0.576,0.769)$ & 86.3 & 4 & $0.642(0.486,0.759)$ & 91.0 \\
\hline PA & 2 & 0.600 & 0 & N/A & $\mathrm{N} / \mathrm{A}$ & $\mathrm{N} / \mathrm{A}$ & 3 & 0.7 & 87 & 2 & $(0.349,0.901)$ & 87.4 \\
\hline DHA & 2 & $0.611(0.525,0.686)$ & 0 & N/A & N/A & N/A & 3 & $0.749(0.616,0.840)$ & 67.4 & N/A & N/A & N/A \\
\hline rans-fat & 4 & $0.604(0.453,0.721)$ & 79.3 & 2 & $0.479(0.385,0.562)$ & 0 & 6 & $0.615(0.419,0.756)$ & 91.0 & 2 & $0.586(-0$ & 93.8 \\
\hline Cholesterol & 48 & $0.657(0.610,0.699)$ & 90.5 & 25 & $0.618(0.560,0.670)$ & 82.1 & 66 & $0.614(0.584,0.642)$ & 79.5 & 37 & $0.556(0.507,0.603)$ & 82.6 \\
\hline Lipid & 4 & $0.701(0.459,0.846)$ & 93.4 & 4 & $0.662(0.370,0.835)$ & 94.5 & 6 & $0.551(0.495,0.603)$ & 0 & 4 & $0.567(0.327,0.738)$ & 83.7 \\
\hline Carbohydrate & 64 & $0.680(0.616,0.735)$ & 96.7 & 23 & $0.641(0.566,0.704)$ & 90.1 & 101 & $0.637(0.609,0.663)$ & 86.3 & 60 & $0.586(0.547,0.622)$ & 83.5 \\
\hline Sucrose & 4 & $0.633(0.533,0.715)$ & 73.1 & 1 & $0.679(0.607,0.741)$ & N/A & 7 & $0.709(0.644,0.764)$ & 67.4 & 1 & $0.632(0.513,0.726)$ & N/A \\
\hline ugal & 8 & $0.707(0.6$ & 81.4 & 1 & $(0.747,0.808)$ & N/A & 11 & 0.6 & 79.2 & 5 & .737) & 88.6 \\
\hline Starch & 2 & $0.510(0.264,0.693)$ & 85.5 & N/A & N/A & N/A & 4 & $0.641(0.604,0.675)$ & 0 & 2 & $0.606(0.553,0.654)$ & 0 \\
\hline Fiber & 54 & $0.683(0.638,0.723)$ & 92.0 & 21 & $5,0.733)$ & 91.1 & 87 & $.609,0.667)$ & 84.5 & 53 & , 0.658) & 83.3 \\
\hline Soluble fiber & 2 & $0.780(0.679,0.852)$ & 94.8 & 1 & $0.499(0.340,0.630)$ & N/A & 14 & $0.658(0.603,0.706)$ & 78.8 & 10 & $0.590(0.493,0.672)$ & 77.0 \\
\hline fiber & 2 & 0.784 & 94.9 & 2 & 0.6 & 84.6 & 12 & 0.64 & 54.9 & 12 & $7,0.670)$ & 74.1 \\
\hline Alcohol & 22 & $0.803(0.749,0.847)$ & 90.1 & 9 & $0.803(0.725,0.860)$ & 88.7 & 47 & $0.851(0.821,0.877)$ & 93.5 & 27 & $0.793(0.746,0.831)$ & 91.0 \\
\hline
\end{tabular}


Table 3 Pooled effect estimates and heterogeneity of the correlation coefficients for the reproducibility of FFQ for micronutrient*

\begin{tabular}{|c|c|c|c|c|c|c|c|c|c|c|c|c|}
\hline \multirow[t]{3}{*}{ Nutrient } & \multicolumn{6}{|c|}{ ICC } & \multicolumn{6}{|c|}{ SCC } \\
\hline & \multicolumn{3}{|c|}{ Crude } & \multicolumn{3}{|c|}{ Energy-adjusted } & \multicolumn{3}{|c|}{ Crude } & \multicolumn{3}{|c|}{ Energy-adjusted } \\
\hline & $\mathbf{N}$ & ICC (95\% CI) & $1^{2}$ & $\mathrm{~N}$ & ICC (95\% Cl) & $1^{2}$ & $\mathrm{~N}$ & ICC $(95 \%$ Cl) & $1^{2}$ & $\mathrm{~N}$ & ICC (95\% CI) & $1^{2}$ \\
\hline itamin A & 27 & $0.623(0.544,0.692)$ & 95.2 & 12 & $0.597(0.464,0.705)$ & 92.2 & 42 & $0.613(0.570,0.651)$ & 87.2 & 22 & $0.553(0.470,0.627)$ & 89.8 \\
\hline tinol & 18 & $0.589(0.513,0.656)$ & 85.3 & 9 & $0.537(0.421,0.635)$ & 74 & 49 & $0.573(0.537,0.607)$ & 80.6 & 38 & $0.513(0.460,0.562)$ & 84.3 \\
\hline Carotene & 9 & $0.632(0.499,0.735)$ & 97.1 & 5 & $0.512(0.328,0.658)$ & 0.86 & 25 & $0.605(0.558,0.649)$ & 89 & 21 & $0.510(0.427,0.584)$ & 90.8 \\
\hline Carotene & 21 & $0.677(0.630,0.719)$ & 76.1 & 6 & $0.613(0.456,0.733)$ & 81.9 & 39 & $0.613(0.573,0.649)$ & 72.3 & 28 & $0.554(0.513,0.593)$ & 56.5 \\
\hline Vitamin C & 47 & $0.665(0.600,0.722)$ & 96.1 & 22 & $0.635(0.526,0.723)$ & 94.9 & 92 & $0.623(0.594,0.650)$ & 85.3 & 57 & $0.596(0.555,0.633)$ & 83.6 \\
\hline D & 16 & $546,0.777)$ & 98.4 & 5 & $0.837)$ & 98.1 & 30 & $0.617(0.5$ & 8 & 15 & 0.5 & .5 \\
\hline Vitamin E & 34 & $0.665(0.576,0.738)$ & 97.5 & 15 & $0.606(0.484,0.704)$ & 94.4 & 52 & $0.626(0.583,0.667)$ & 91.4 & 30 & $0.555(0.490,0.613)$ & 87 \\
\hline Vitamin K & 3 & $0.656(0.430,0.804)$ & 97.4 & 2 & $0.693(0.652,0.729)$ & 0 & 7 & $0.602(0.511,0.679)$ & 60.4 & 5 & $0.658(0.553,0.742)$ & 32.7 \\
\hline iamin & 31 & $0.630(0.587,0.670)$ & 87.3 & 12 & $0.606(0.492,0.699)$ & 93.1 & 55 & $0.606(0.579,0.633)$ & 74.3 & 39 & $0.522(0.475,0.566)$ & 79.5 \\
\hline Riboflavin & 28 & $0.667(0.616,0.712)$ & 91.7 & 10 & $0.619(0.483,0.726)$ & 94.7 & 54 & $0.640(0.611,0.667)$ & 81 & 35 & $0.581(0.528,0.628)$ & 85.4 \\
\hline acin & 22 & $0.667(0.609,0.718)$ & 89.4 & 10 & $0.605(0.499,0.693)$ & 90.7 & 39 & $0.643(0.573,0.704)$ & 94.3 & 34 & $0.517(0.452,0.576)$ & 2 \\
\hline Vitamin B6 & 13 & $0.723(0.522,0.847)$ & 98.4 & 5 & $0.712(0.516,0.838)$ & 96.6 & 27 & $0.610(0.553,0.662)$ & 78.8 & 19 & $0.555(0.483,0.619)$ & 77.2 \\
\hline olate & 25 & $0.637(0.582,0.686)$ & 90.5 & 6 & $0.684)$ & 76.4 & 19 & $0.612(0.5$ & 1.6 & 26 & ) & 5 \\
\hline Vitamin B12 & 13 & $0.678(0.507,0.797)$ & 97.7 & 7 & $0.683(0.496,0.809)$ & 96.8 & 28 & $0.635(0.577,0.686)$ & 82.3 & 21 & $0.575(0.490,0.648)$ & 87.5 \\
\hline Se & 11 & $0.661(0.608,0.709)$ & 69.3 & 4 & $0.586(0.429,0.709)$ & 78.7 & 15 & $0.648(0.586,0.702)$ & 82.4 & 11 & $0.568(0.446,0.670)$ & 87.6 \\
\hline $\mathrm{Mg}$ & 19 & $0.674(0.612,0.728)$ & 88.4 & 6 & $0.617(0.492,0.717)$ & 87.5 & 30 & $0.669(0.603,0.725)$ & 89.9 & 19 & $0.629(0.544,0.701)$ & 86.8 \\
\hline $\mathrm{Ca}$ & 52 & $0.635(0.588,0.676)$ & 91.8 & 23 & $0.642(0.566,0.708)$ & 91 & 87 & $0.622(0.594,0.649)$ & 83 & 55 & $0.586(0.545,0.626)$ & 841 \\
\hline $\mathrm{Fe}$ & 39 & $0.640(0.581,0.692)$ & 93.9 & 19 & $0.564(0.496,0.625)$ & 79.4 & 75 & $0.613(0.582,0.642)$ & 83.8 & 47 & $0.570(0.525,0.612)$ & 82.8 \\
\hline I & 2 & $0.499(0.338,0.632)$ & 73.7 & 3 & $0.507(0.421,0.585)$ & 35 & 2 & $0.828(0.724,0.894)$ & 19.8 & 1 & $0.744(0.600,0.841)$ & N/A \\
\hline $\mathrm{Zn}$ & 26 & $0.595(0.556,0.631)$ & 68.8 & 12 & 441) & 72.3 & 26 & $65,0.675)$ & 85.3 & 18 & 675) & r \\
\hline $\mathrm{Cu}$ & 4 & $0.658(0.620,0.693)$ & 0 & 1 & $0.690(0.646,0.728)$ & $\mathrm{N} / \mathrm{A}$ & 6 & $0.748(0.620,0.837)$ & 86.6 & 5 & $0.726(0.608,0.813)$ & 86.6 \\
\hline K & 25 & $0.672(0.598,0.736)$ & 95.4 & 7 & $486,0.752)$ & 93.6 & 49 & $0.637(0.605,0.667)$ & 80 & 34 & $0.608(0.566,0.647)$ & 73.4 \\
\hline$P$ & 23 & $0.605(0.521,0.676)$ & 91.9 & 9 & $0.635(0.544,0.711)$ & 80.7 & 43 & $0.621(0.575,0.662)$ & 83.4 & 30 & $0.579(0.521,0.630)$ & 82.1 \\
\hline $\mathrm{Na}$ & 25 & $0.652(0.499,0.766)$ & 98.2 & 8 & $0.670(0.474,0.802)$ & 97 & 41 & $0.623(0.582,0.661)$ & 83.9 & 30 & $0.552(0.489,0.609)$ & 86.7 \\
\hline $\mathrm{Mn}$ & 2 & $0.621(0.382,0.781)$ & 64.8 & N/A & N/A & N/A & 5 & $0.655(0.596,0.707)$ & 0 & 2 & $0.719(0.645,0.779)$ & 0 \\
\hline
\end{tabular}

${ }^{a} \mathrm{Cl}$ confidence interval, $I^{2}$ inconsistency index, $N / A$ not available

adjusted ICCs varied from 0.589 (retinol) to 0.723 (vitamin B6) and from 0.512 (carotene) to 0.712 (vitamin B6), respectively; values generally exceeded 0.5 . The median crude SCC was 0.613 with a range from 0.573 (retinol) to 0.643 (niacin). The median energy-adjusted SCC was 0.38 with a range from 0.510 (carotene) to 0.658 (vitamin K). For mineral intake, the crude and energy-adjusted ICCs ranged from 0.499 to 0.674 (median: 0.640 ) and from 0.507 to 0.690 (median: 0.626), respectively; the crude and energy-adjusted SCCs ranged from 0.613 to 0.828 (median: 0.637 ) and from 0.552 to 0.744 (median: 0.597), respectively. The heterogeneity of correlation coefficients for most micronutrients was high $\left(\mathrm{I}^{2}>75 \%\right)$.

\section{Subgroup analysis according to age and sex}

To assess the impact of age on the degree of reproducibility of two FFQ measures, we performed subgroup analysis according to age (Fig. 2). As shown in Supplemental Table 2, compared with those for adults aged between 18 and 50 years (median: 0.671, range: 0.5100.793 ), the ICCs of reproducibility were lower in adolescents $(<18$ years) except those for retinol and vitamin $D$ (median: 0.524, range: 0.290-0.730). The median (range) of ICCs for the elderly (> 50 years) was 0.659 ( 0.482 0.866), which were lower than those for adults for 22 of 40 nutrients. For pooled SCCs (Supplemental Table 3), the median (range) values between repeated measures was 0.646 (0.516-0.837), $0.608(0.339-0.873)$, and 0.469 (0.480-0.724) for adults, the elderly, and adolescents, respectively. SCCs were lower in adolescents than in adults for most nutrients except $\mathrm{K}, \mathrm{Na}$, and lipid. Values were higher in adults than in the elderly for 34 of 45 nutrients.

Based on subgroup analysis according to sex (Fig. 3), pooled ICCs for estimation of 13 of 28 and pooled SCCs 


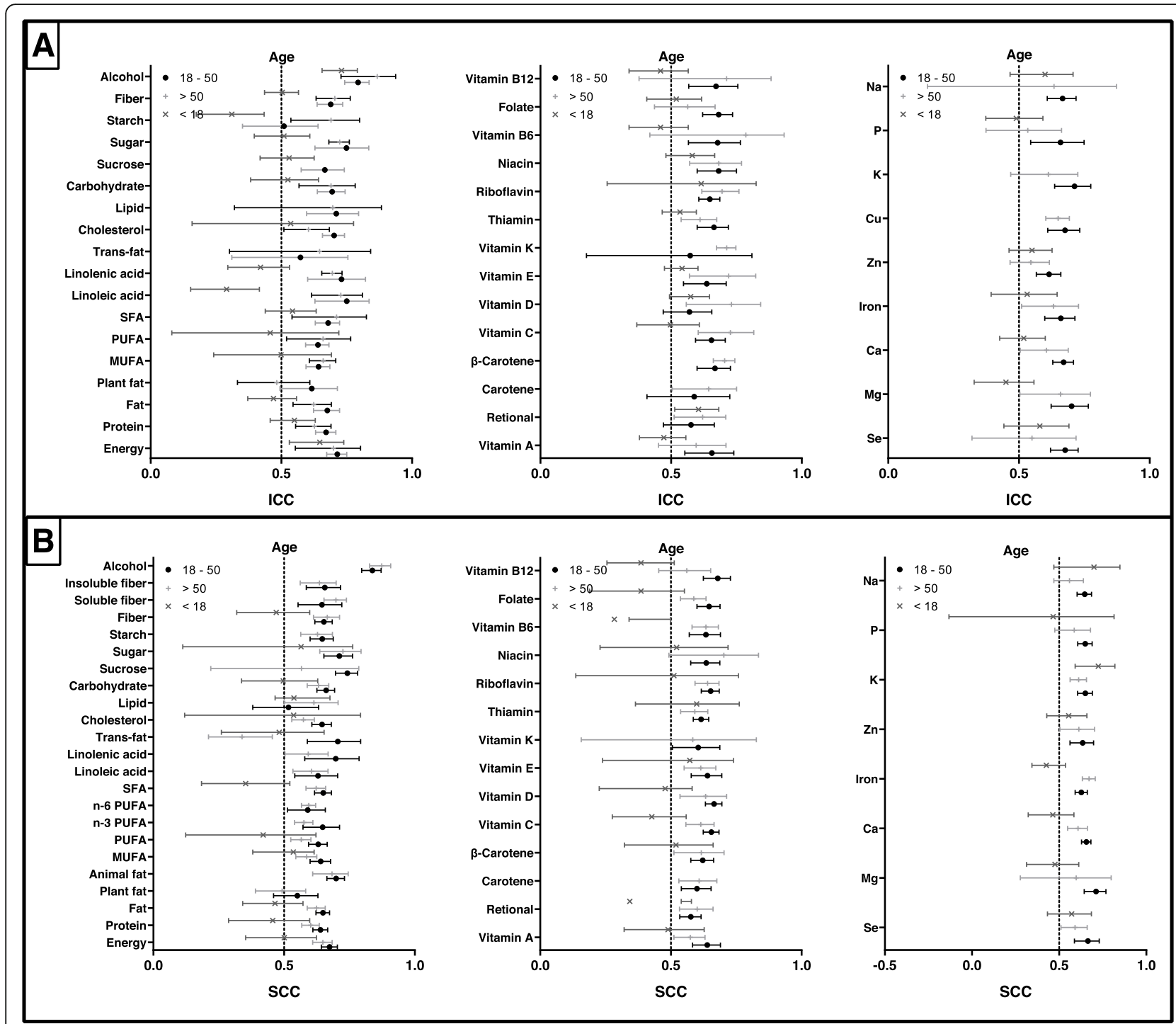

Fig. 2 Reproducibility of food frequency questionnaires (FFQ) stratified by age. Values represent pooled intraclass correlation coefficient (ICC) and spearman correlation coefficient (SCC), with 95\% confidence intervals. The results of ICCs were present in (a) and the results of SCCs were present in (b)

for estimation of 17 of 46 nutrient intake between two measures were higher in men than in women. The median pooled crude ICC was 0.668 (range: $0.489-0.839$ ) and 0.666 (range: $0.410-0.819$ ) for men and women (Supplemental Table 4). Range of SCCs was between 0.374 and 0.872 for men, and between 0.502 and 0.838 for women (Supplemental Table 5).

\section{Subgroup analysis according to region}

Subgroup analysis according to region revealed that the ICCs of reproducibility ranged from 0.369 (retinol) to 0.829 (thiamin), $0.560(\mathrm{Zn})$ to 0.830 (alcohol), 0.400 (vitamin $\mathrm{K}$ ) to 0.839 ( $\beta$-carotene), 0.310 (starch) to 0.859 (lipid), and 0.563 (vitamin D) to 0.861 (alcohol) in the regions of Africa, Oceania, Asia, Europe, and America, respectively (Supplemental Table 6 and Table 7). As shown in Supplemental Table 8 and Table 9, pooled crude SCCs ranged from 0.283 (vitamin B6) to $0.723(\mathrm{Na})$ for Africa, 0.514 (vitamin A) to 0.907 (alcohol) for Oceania, 0.537 (lipid) to 0.809 (linolenic acid) for Asia, 0.487 (plant fat) to 0.857 (alcohol) for Europe, and 0.413 (vitamin K) to 0.872 (alcohol) for America.

\section{Factors influencing reproducibility according to study design}

The results of pooled ICCs and SCCs for reproducibility stratified according to sample size are presented in Fig. 4. The results of pooled ICCs stratified according to sample size are presented in Supplemental Table 10. The median 


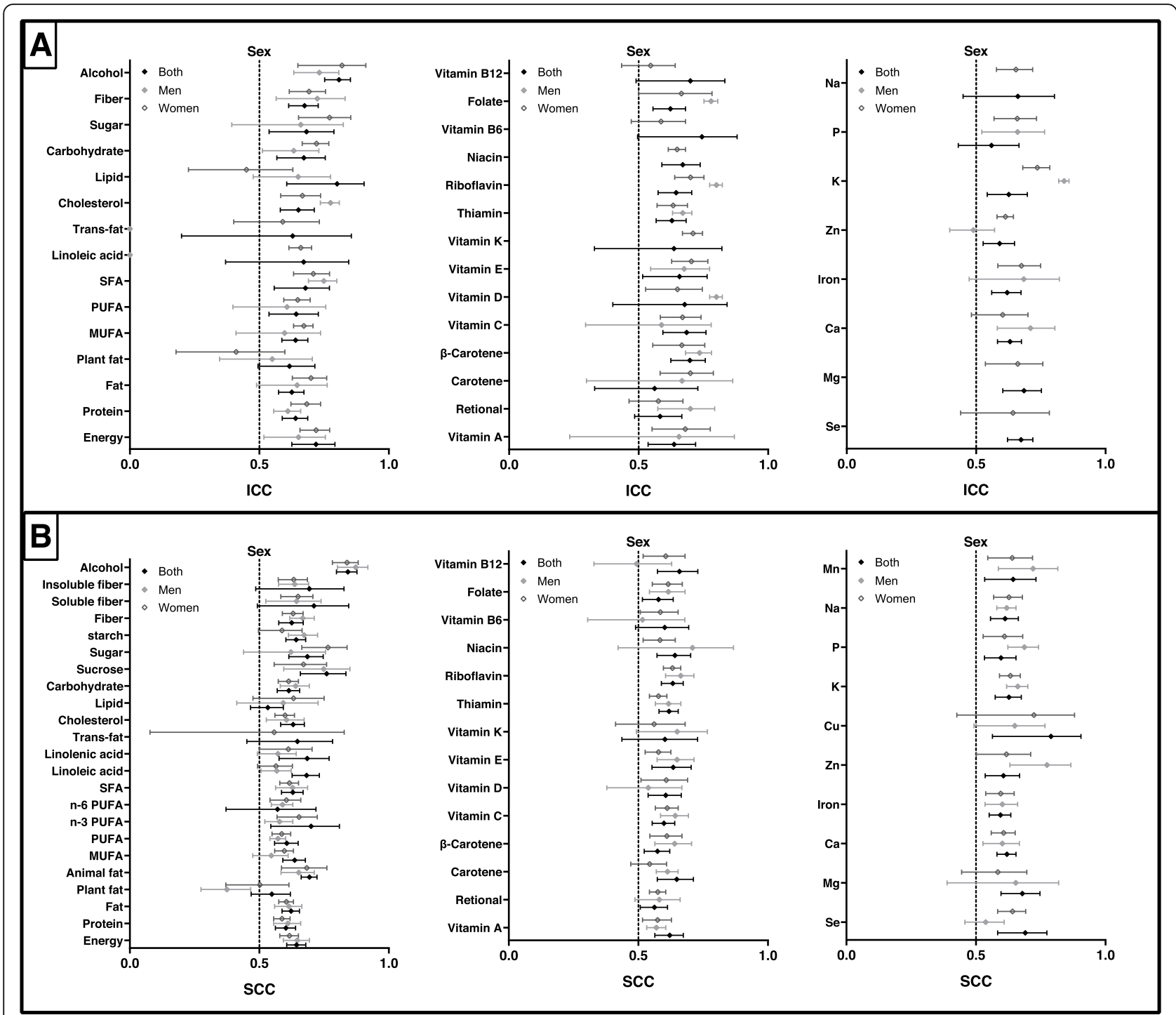

Fig. 3 Reproducibility of food frequency questionnaires (FFQ) stratified by sex. Values represent pooled intraclass correlation coefficient (ICC) and spearman correlation coefficient (SCC), with 95\% confidence intervals. The results of ICCs were present in (a) and the results of SCCs were present in (b)

(range) of ICCs in small $(\leq 112)$ and large sample sizes $(>$ $112)$ were $0.678(0.529-0.818)$ and $0.636(0.310-0.764)$, respectively. The ICCs of reproducibility for small sample sizes were higher than those for large sample size for 30 of 39 nutrients. When SCCs were used to assess the reproducibility of FFQs, the values ranged from 0.482 to 0.855 for large sample sizes. The values for small sample sizes varied from 0.516 to 0.841 , which were higher than those of large sample sizes for most nutrients (28/46) (Supplemental Table 11).

The results of analysis of subgroups by interval time between two measures of FFQs is present in Fig. 5. And we found that a median (range) of pooled ICCs of 0.643 (0.518-0.822) for short-term reproducibility and 0.652 (0.485-0.788) for long-term reproducibility (Supplemental Table 12). SCCs ranged from 0.532 to 0.860 and 0.339 to
0.840 for short-term and long-term reproducibility, respectively (Supplemental Table 13). For participants with a shorter period ( $\leq 6$ months) between completing FFQs, pooled ICCs of energy and most nutrient (24/40) intake were higher than those for longer periods ( $>6$ months). Higher SCCs were identified for most nutrients $(42 / 48)$ for assessment of the short-term reliability of FFQs when compared with those for long-term reliability.

In order to assess the influence of seasons on the reproducibility of FFQs, we conducted a subgroup analysis with 12-month interval as cut-point. For the long-term and short-term reproducibility of FFQ, the pooled ICC was from 0.501 to 0.859 (median $=0.676$ ) and from 0.485 to 0.788 (median $=0.643$ ), respectively (Supplemental Table 14). Compared with the reproducibility of 


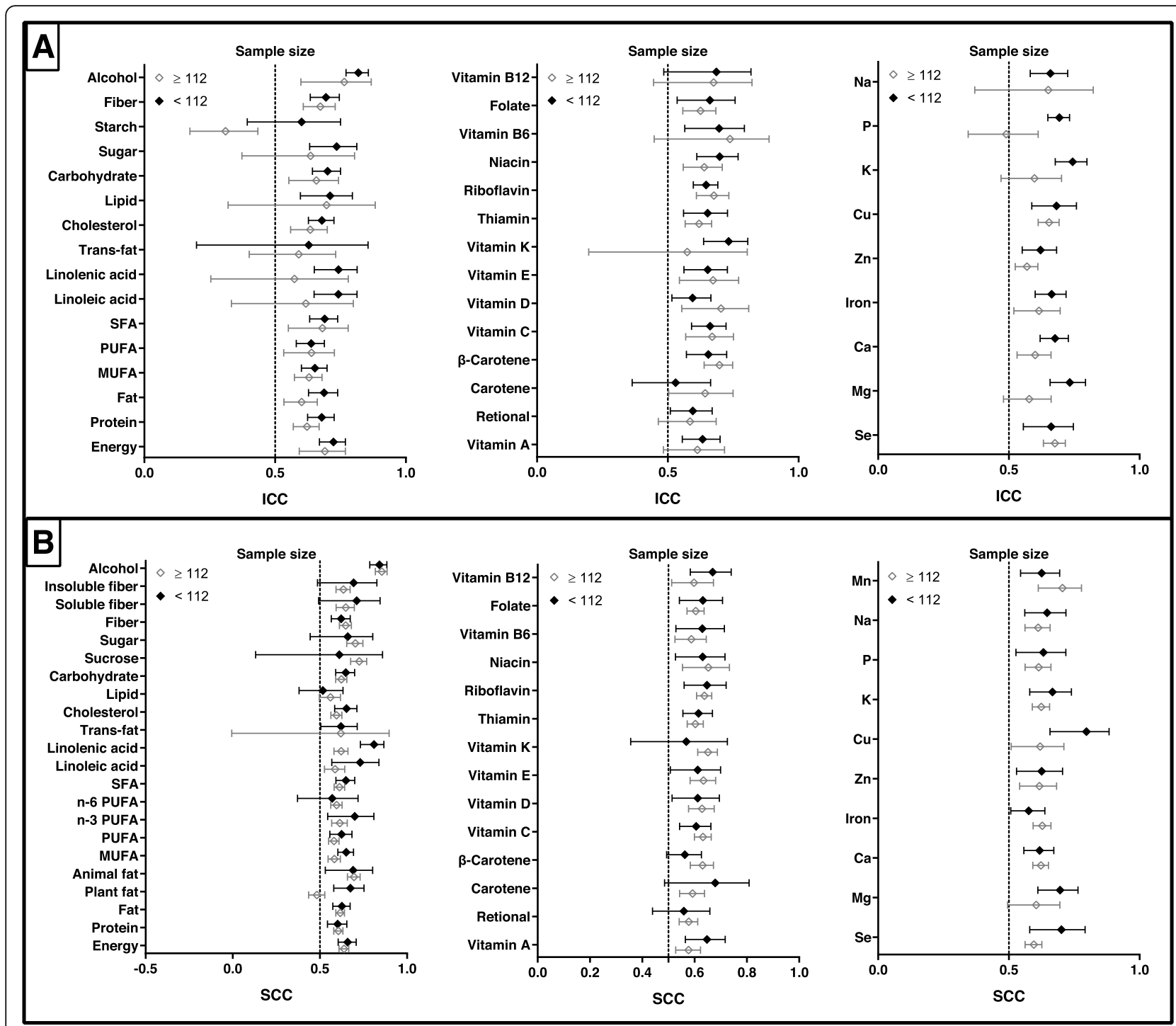

Fig. 4 Reproducibility of food frequency questionnaires (FFQ) stratified by sample size. Values represent pooled intraclass correlation coefficient (ICC) and spearman correlation coefficient (SCC), with 95\% confidence intervals. The results of ICCs were present in (a) and the results of SCCS were present in (b)

FFQs at long time intervals ( $\geq 12$ months), the ICCs of FFQs reproducibility at short intervals were higher (28/ 40). As shown in Supplemental Table 15, the SCCs of reproducibility of FFQ at long intervals ( $\geq 12$ months) were from 0.339 to 0.848 (median $=0.602$ ) and SCCs of reproducibility of FFQ at short intervals $(<12$ months) were from 0.248 to 0.845 (median $=0.632$ ). The SCCs for short-term reproducibility of FFQs were higher for energy and most nutrients (34/49) than long-term reproducibility of FFQs.

\section{Factors influencing reproducibility according to FFQ design}

The results of subgroup analyses according to items of FFQ are presented in Fig. 6. For FFQ items, the pooled ICCs between two measures of FFQs with many items $(>120)$ varied from 0.512 to 0.825 , whereas values of FFQs with small items $(\leq 120)$ ranged from 0.310 to 0.764 (Supplemental Table 16). The pooled SCCs of long FFQs varied from 0.555 to 0.85 , while the values of short FFQs ranged from 0.469 to 0.851 (Supplemental Table 17). Compared with those of short FFQs, pooled ICCs and SCCs of long FFQs were higher for 38 of 39 nutrients and 43 of 49 nutrients, respectively.

ICCs and SCCs for reproducibility stratified according to dietary recall interval are presented in Fig. 7 . The median ICC values were 0.659 (range: $0.557-0.836$ ) for long-term FFQs ( $\geq 12$ months) and 0.622 (range: 0.310 0.854 ) for short-term FFQs (<12 months). SCCs ranged from 0.522 to 0.847 and 0.494 to 0.838 for long-term and short-term FFQs, respectively. The combined ICCs of 24/38 nutrients and SCCs of 20/42 nutrients between 


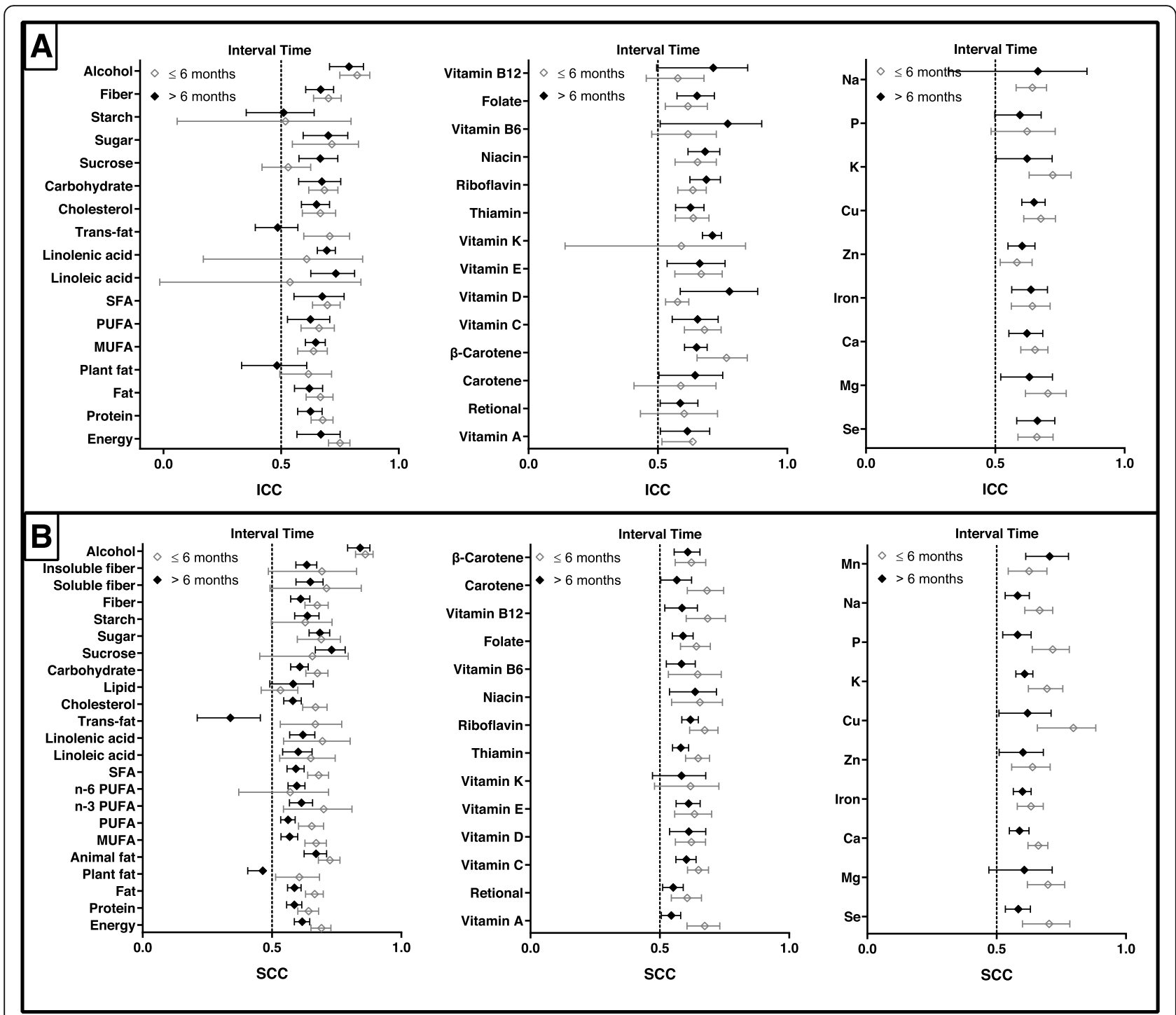

Fig. 5 Reproducibility of food frequency questionnaires (FFQ) stratified by interval time. Values represent pooled intraclass correlation coefficient (ICC) and spearman correlation coefficient (SCC), with 95\% confidence intervals. The results of ICCs were present in (a) and the results of SCCS were present in (b)

repeated long-term FFQs were higher than those for short-term FFQs (Supplemental Table 18 and Table 19).

Figure 8 present the difference of correlations between self-administered and interviewer-administered FFQs. Pooled ICCs ranged from 0.530 to 0.811 and 0.502 to 0.826 for the reproducibility of self-administered FFQs and interviewer-administered FFQs, respectively (Supplemental Table 20). In total, values for 17/39 nutrients were higher for self-administered FFQs than for intervieweradministered FFQs. SCCs for the reproducibility of selfadministered FFQs (range: 0.553-0.874) were higher than those for interviewer-administered FFQs (range: 0.4820.761) for 37 of 43 nutrients (Supplemental Table 21).

\section{Discussion}

In the present study, we conducted a meta-analysis to systematically assess the reproducibility of FFQs and to explore the factors related to the reproducibility of FFQs. And the pooled ICCs and SCCs were found exceeded 0.5 for energy and most nutrients in general heathy populations. For the elderly and adolescents, pooled ICCs and SCCs for most nutrients were lower than those in adults (18-50 years old). In terms of energy and 24 macronutrients, all ICC and SCC values exceeded 0.5, except for I, soluble fiber, trans-fat, n-3 PUFA, and n-6 PUFA. Moreover, we identified that FFQs with more food items, 12 months as dietary recall 


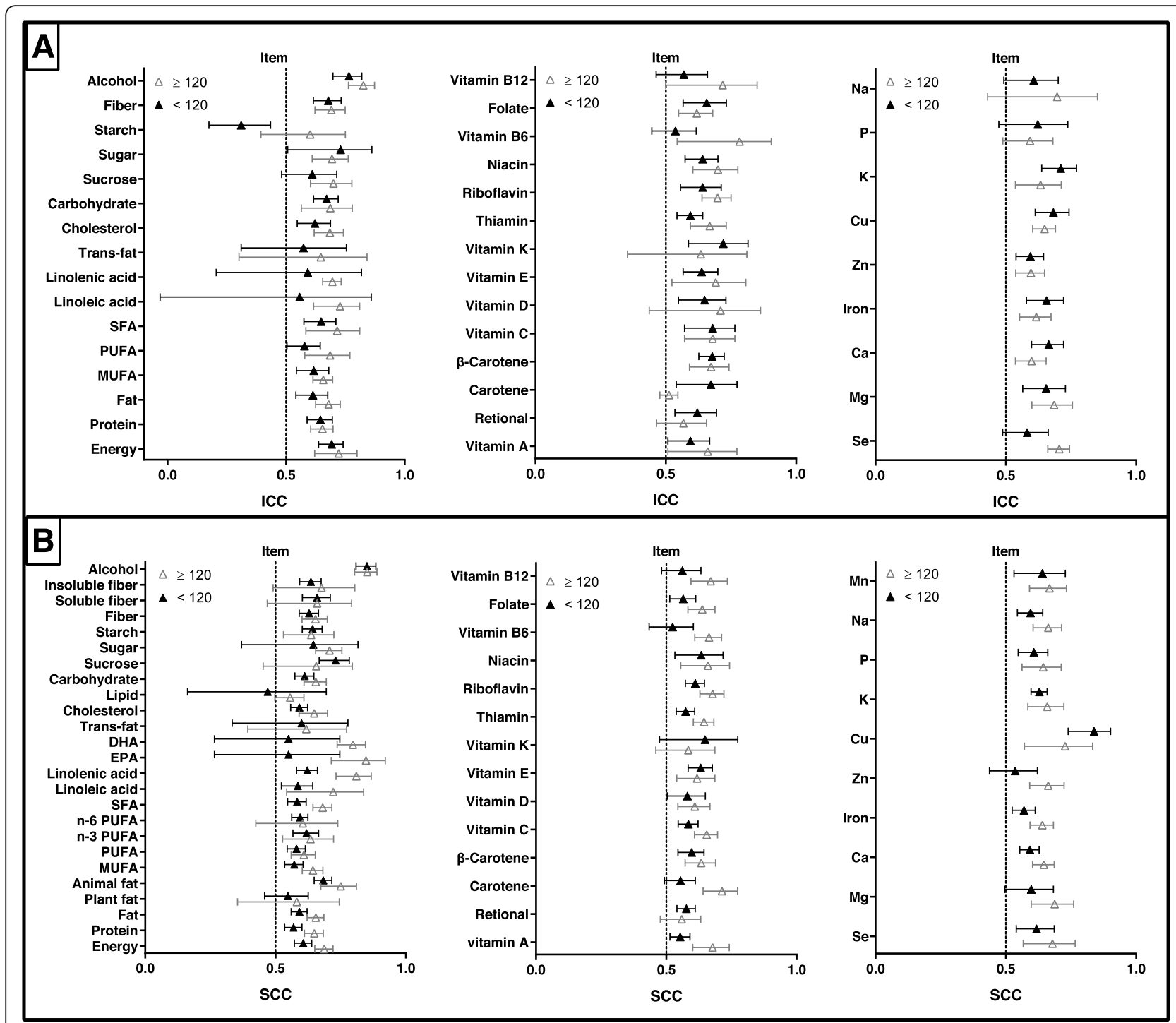

Fig. 6 Reproducibility of food frequency questionnaires (FFQ) stratified by items of FFQ. Values represent pooled intraclass correlation coefficient (ICC) and spearman correlation coefficient (SCC), with 95\% confidence intervals. The results of ICCs were present in (a) and the results of SCCS were present in (b)

interval, and shorter time periods between repeated FFQs resulted in superior FFQ reproducibility.

To evaluate the ability of FFQs to accurately evaluate long-term dietary intake in different age groups, we conducted subgroup analysis according to age which revealed that the correlations of the reproducibility of FFQs exceeded 0.5 for most nutrients in the elderly, adolescents, and adults, indicating that the reliability of FFQs was relatively consistent across age groups. However, the reproducibility of FFQs for adults was higher than that for the elderly and adolescents for most nutrients. A potential reason for the lower correlation in adolescents was that older individuals may have more established dietary habits than younger individuals [55]. Further, in adolescents, it is more challenging to assess dietary intake levels, particularly for cooking-related ingredients such as spices [123], and to understand abstract concepts of average intake, particularly for seasonal food such as fruits [37], although the ability to self-report food intake in adolescents improves rapidly from 8 years of age [135]. Compared with that in adults, the reproducibility of FFQs in the elderly tended to be poor. Although the elderly have a relatively stable dietary intake, a decline in memory or cognitive function may have contributed to the tendency for poor reproducibility in the elderly [70].

Gender differences in the reproducibility of FFQs were observed in this study. The degree of reproducibility was generally higher in women than in men for 


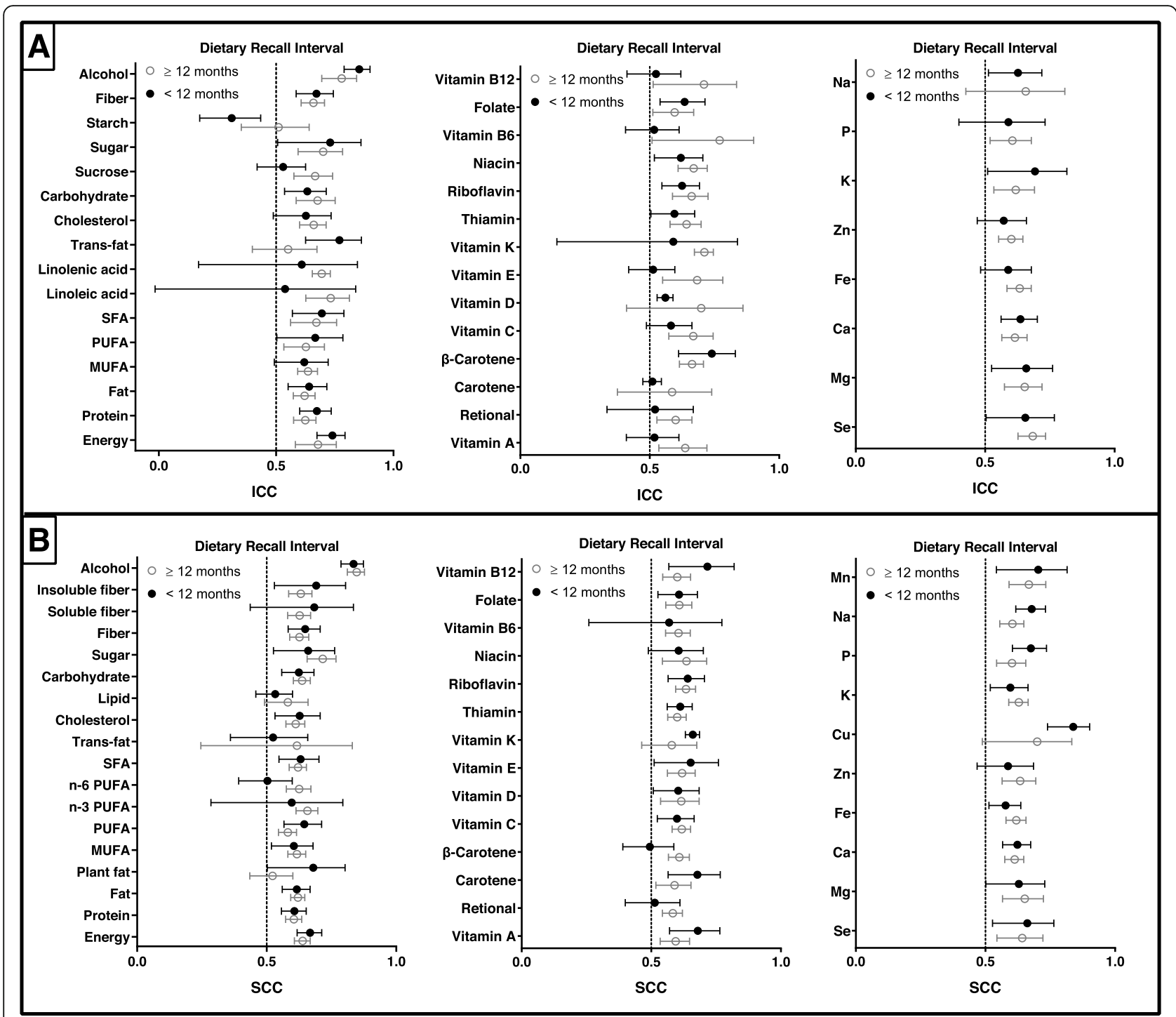

Fig. 7 Reproducibility of food frequency questionnaires (FFQ) stratified by dietary recall interval. Values represent pooled intraclass correlation coefficient (ICC) and spearman correlation coefficient (SCC), with 95\% confidence intervals. The results of ICCs were present in (a) and the results of SCCs were present in (b)

most nutrients, suggesting that women have more stable long-term dietary intake than that of men [21]. Generally, women pay more attention to food intake and cook more often [79], which may contribute to the higher reproducibility of FFQs in women.

In addition, we observed that the reproducibility of FFQ was low when the sample size was large. This low correlation was not the true reproducibility coefficients between FFQs, but might be caused by irrelevant factors in the operation process. As the large sample sizes may facilitate the management of more participants; consume time, resources, and effort; induce loss to follow-up and put a burden on researchers. However, a small sample size may limit representativeness, which induces large differences in within-person nutrient intakes, leading to less reliable correlation coefficients and ICCs [122]. Therefore, when conducting FFQ reproducibility research, a sample size with sufficient statistical power is recommended to ensure reproducibility of FFQs, rather than increasing sample size blindly.

FFQs with more items presented better reproducibility for most nutrients, indicating that long FFQs collated more reliable information [136] and enabled better estimations of dietary and nutrient consumption [92]. However, participants require more time to accurately complete the questionnaire and may lose patience, leading to potential biases and, ultimately, data of lower quality [2]. Therefore, to balance reporting errors and reproducibility of FFQs, pilot studies should be 


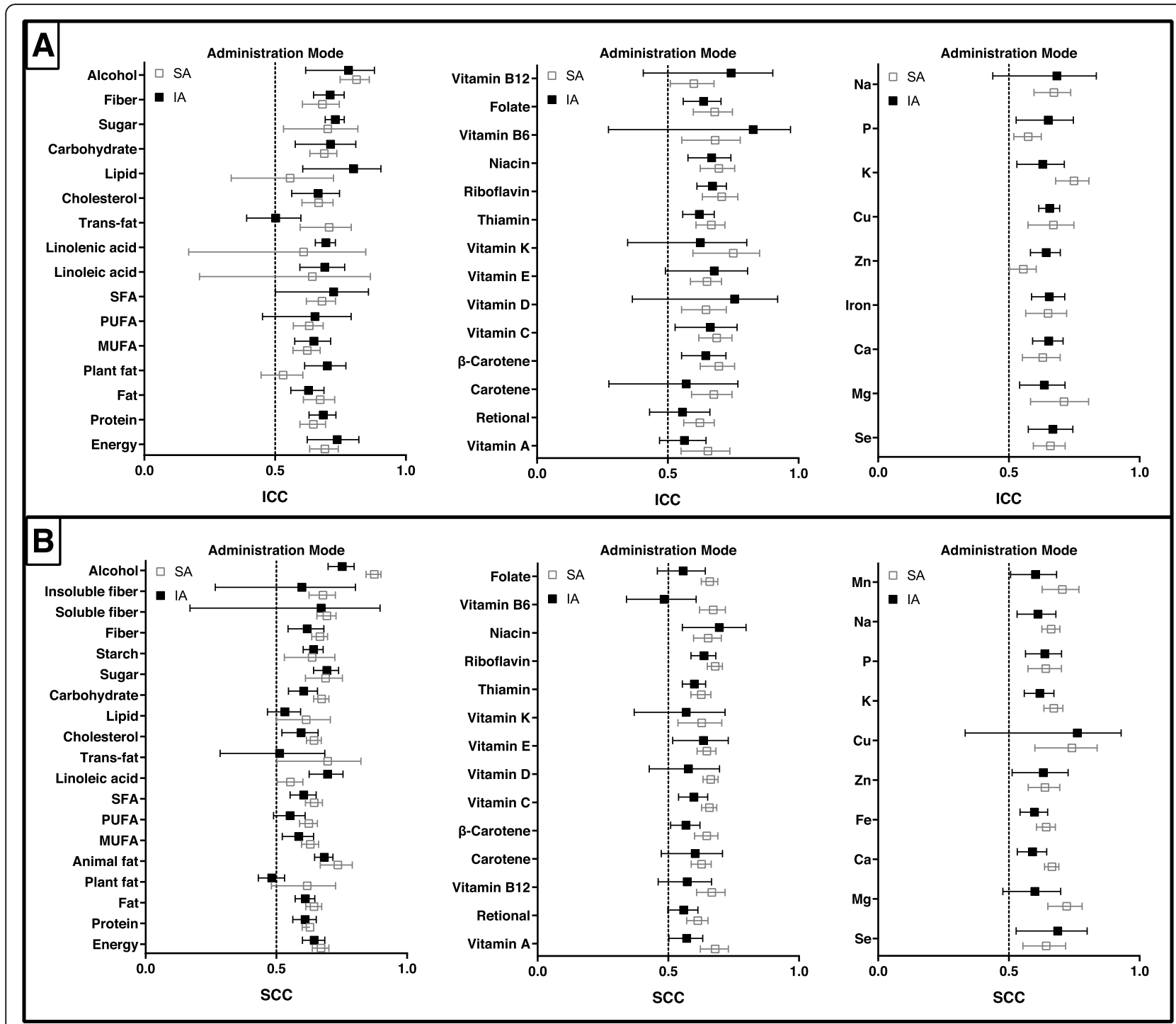

Fig. 8 Reproducibility of food frequency questionnaires (FFQ) stratified by administration mode. Values represent pooled intraclass correlation coefficient (ICC) and spearman correlation coefficient (SCC), with 95\% confidence intervals. The results of ICCs were present in (a) and the results of SCCs were present in (b)

performed to explore the appropriate number of FFQ items based on the demographic characteristics of participants.

FFQs were used to assess regular dietary habits over extended periods. The correlation coefficients of the study assessing the reproducibility of FFQs over more than a 1-year period were higher than those over short periods for most nutrients. Relatively high correlations for 1 year indicated that FFQs can provide an accurate estimation of long-term dietary habits. The reasons for lower correlations of FFQs over less than 1 year may be related to the seasonal availability of food [130]. In addition, it is useful for researchers to assess the complete dietary intake of participants with 1 year as the reference time for FFQs [130].
The combined correlation coefficients were higher when FFQs were administered over a short period $(\leq 6$ months) compared with those over a long time interval ( $>6$ months), suggesting that shorter intervals between repeated FFQ administrations were a key factor contributing to high reproducibility of FFQs, in accordance with a previous review [2]. A possible explanation for the higher correlations for short-term reproducibility is that it is easier for respondents to remember and replicate their previous FFQ responses accurately when two FFQs are administered closely in time [15]. The difference between the two subgroups may also be because of changes in diet over time [137]. The lower correlation of long-term reproducibility suggested that the participants' usual intake of food may have changed during the study 
period [134]. Because food intake also exhibits yearly trends [138, 139], longer intervals between repeated FFQs were selected to avoid the effects of seasonal or yearly variations in diet [82]. Therefore, before selecting intervals between repeated FFQs, memory bias and seasonal changes in diet should be taken into consideration.

The main strength of this study is that it is the first meta-analysis to comprehensively analyze FFQ reproducibility. Current research is based on a large number of different populations with a wide age range which revealed good reproducibility of nutrient intake, making FFQs suitable for analyzing dietary intake among different subgroups of age, sample size, gender, and region. We comprehensively evaluated the reproducibility of FFQs by analyzing the intake of 50 nutrients, which strengthened the conclusions of this study.

This study has some limitations. First, our screening criteria excluded articles that assessed the effectiveness of specific nutrients, which may have affected our results in different ways. Second, learning ability and lifestyles, such as education level and body mass index, may have influenced FFQ reliability. However, the relevant data were not available in the included articles. Third, we did not evaluate the quality of included studies because there are currently no tools to assess the quality of reproducibility studies for FFQs. Further studies are needed to establish such tools to evaluate the quality of reproducibility studies for FFQ.

\section{Conclusions}

In conclusion, FFQs with correlation coefficients greater than 0.5 for most nutrients may be considered a reliable tool to measure dietary intake. In addition, factors related to FFQ design may be associated with the reproducibility of FFQs, such as FFQ items and dietary recall intervals. To increase the reproducibility of FFQs, the following points should be considered before developing FFQs. First, pilot studies are warranted to explore the appropriate number of FFQ items based on the characteristics of the study population. Second, 12 months is suggested as the dietary recall interval. Third, when performing reproducibility studies for FFQs, a sample size with sufficient statistical power, but no larger, is recommended.

\section{Supplementary Information}

The online version contains supplementary material available at https://doi. org/10.1186/s12966-020-01078-4.

Additional file 1. PRISMA Checklist

Additional file 2 Supplemental Table 1. The overview of the retrieved studies assessing the reproducibility of FFQs.

Additional file $\mathbf{3}$ Supplemental Table 2. Pooled intraclass correlation coefficients for energy and nutrients stratified by age.
Additional file $\mathbf{4}$ Supplemental Table 3. Pooled spearman correlation coefficients for energy and nutrients stratified by age.

Additional file $\mathbf{5}$ Supplemental Table 4. Pooled intraclass correlation coefficients for energy and nutrients stratified by sex.

Additional file 6 Supplemental Table 5. Pooled spearman correlation coefficients for energy and nutrients stratified by sex.

Additional file $\mathbf{7}$ Supplemental Table 6. Pooled crude intraclass correlation coefficients for energy and nutrients stratified by regions.

Additional file 8 Supplemental Table 7. Pooled energy-adjusted intraclass correlation coefficients for energy and nutrients stratified by regions.

Additional file 9 Supplemental Table 8. Pooled crude spearman correlation coefficients for energy and nutrients stratified by regions.

Additional file $\mathbf{1 0}$ Supplemental Table 9. Pooled energy-adjusted spearman correlation coefficients for energy and nutrients stratified by regions.

Additional file 11 Supplemental Table 10. Pooled intraclass correlation coefficients for energy and nutrients stratified by sample size.

Additional file 12 Supplemental Table 11. Pooled spearman correlation coefficients for energy and nutrients stratified by sample size.

Additional file $\mathbf{1 3}$ Supplemental Table 12. Pooled intraclass correlation coefficient for energy and nutrients stratified by time interval (6 months as cut-point).

Additional file 14 Supplemental Table 13. Pooled spearman correlation coefficient for energy and nutrients stratified by time interval (6 months as cut-point).

Additional file 15 Supplemental Table 14. Pooled intraclass correlation coefficient for energy and nutrients stratified by time interval (12 months as cut-point).

Additional file $\mathbf{1 6}$ Supplemental Table 15. Pooled spearman correlation coefficient for energy and nutrients stratified by time interval (12 months as cut-point).

Additional file 17 Supplemental Table 16. Pooled intraclass correlation coefficient for energy and nutrients stratified by items of FFQ.

Additional file 18 Supplemental Table 17. Pooled spearman correlation coefficient for energy and nutrients stratified by items of FFQ. Additional file 19 Supplemental Table 18. Pooled intraclass correlation coefficient for energy and nutrients stratified by dietary recall interval.

Additional file 20 Supplemental Table 19. Pooled spearman correlation coefficient for energy and nutrients stratified by dietary recall interval.

Additional file 21 Supplemental Table 20. Pooled intraclass correlation coefficient for energy and nutrients stratified by administration mode.

Additional file 22 Supplemental Table 21. Pooled spearman correlation coefficient for energy and nutrients stratified by administration mode.

\section{Abbreviations}

$I^{2}$ : Inconsistency index; ICCs: Intraclass coefficients; I: Iodine; K: Potassium; Na: Sodium; SCC: Spearman correlation coefficients; Zn: Zinc

Acknowledgements

We are grateful to all the participants of the study.

\section{Authors' contributions}

Yang Xia and Qi Cui. contributed to the study conception and design. Q Cui, Yang Xia, Qijun Wu and Qing Chang contributed to data collection, analysis and interpretation of the data. Qi Cui contributed to manuscript drafting. Yang Xia, Kaijun Niu, and Yuhong Zhao contributed to the revising of the manuscript; Kaijun Niu and Yuhong Zhao contributed to the approval of the final version of the manuscript. 


\section{Funding}

This work was supported by the National Key R\&D Program of China under Grant 2017 YFC0907402 to Yuhong Zhao; the National Natural Science Foundation of China under Grant 81903302 to Yang Xia; the China Postdoctoral Science Foundation under Grant 2018M641753 to Yang Xia; and the 345 Talent Project of Shengjing Hospital of China Medical University under Grant M0294 to Yang Xia. The funding body had no role in the study design; collection, analysis, and interpretation of data; or writing of the manuscript.

\section{Availability of data and materials}

Not applicable.

\section{Ethics approval and consent to participate}

Not applicable.

\section{Consent for publication}

Not applicable.

\section{Competing interests}

The authors declare that they have no competing interests.

Received: 30 August 2020 Accepted: 17 December 2020

Published online: 11 January 2021

\section{References}

1. Shim JS, Oh K, Kim HC. Dietary assessment methods in epidemiologic studies. Epidemiol Health. 2014;36:e2014009.

2. Cade J, Thompson R, Burley V, Warm D. Development, validation and utilisation of food-frequency questionnaires - a review. Public Health Nutr. 2002:5:567-87.

3. Kaaks R, Slimani N, Riboli E. Pilot phase studies on the accuracy of dietary intake measurements in the EPIC project: overall evaluation of results. European Prospective Investigation into Cancer and Nutrition. Int J Epidemiol. 1997;26(Suppl 1):S26-36.

4. Franceschi S, Barbone F, Negri E, Decarli A, Ferraroni M, Filiberti R, Giacosa A, Gnagnarella P, Nanni O, Salvini S, et al. Reproducibility of an Italian food frequency questionnaire for cancer studies. Results for specific nutrients. Ann Epidemiol. 1995;5:69-75.

5. Kaaks R, Slimani N, Riboli E. Temporal change in the reproducibility of a selfadministered food frequency questionnaire. Int J Epidemiol. 1997;26(Suppl 1):S26-36.

6. Nagata C, Ohwaki A, Kurisu Y, Shimizu H. Food diversity and validity of semiquantitative food frequency questionnaire. J Epidemiol. 1998;8:297-301.

7. Cade JE, Burley VJ, Warm DL, Thompson RL, Margetts BM. Food-frequency questionnaires: a review of their design, validation and utilisation. Nutr Res Rev. 2004;17:5-22

8. Tsubono Y, Nishino Y, Fukao A, Hisamichi S, Tsugane S. Temporal change in the reproducibility of a self-administered food frequency questionnaire. Am J Epidemiol. 1995;142:1231-5.

9. Shrestha A, Koju RP, Beresford SAA, Chan KCG, Connell FA, Karmacharya BM, Shrestha P, Fitzpatrick AL. Reproducibility and relative validity of food group intake in a food frequency questionnaire developed for Nepalese diet. Int J Food Sci Nutr. 2017;68:605-12.

10. Turconi G, Bazzano R, Roggi C, Cena H. Reliability and relative validity of a quantitative food-frequency questionnaire for use among adults in Italian population. Int J Food Sci Nutr. 2010;61:846-62.

11. Li K, Takezaki T, Lv LW, Yu P, Song FY, Tajima K. Reproducibility of a semiquantitative food frequency questionnaire in Chaoshan area, China. Asian Pac J Cancer Prev. 2005;6:521-6.

12. Hebden L, Kostan E, O'Leary F, Hodge A, Allman-Farinelli M. Validity and reproducibility of a food frequency questionnaire as a measure of recent dietary intake in young adults. PLoS One. 2013;8:e75156.

13. Takachi R, Ishihara J, Iwasaki M, Hosoi S, Ishii Y, Sasazuki S, Sawada N, Yamaji T, Shimazu T, Inoue M, Tsugane S. Validity of a self-administered food frequency questionnaire for middle-aged urban cancer screenees: comparison with 4-day weighed dietary records. J Epidemiol. 2011;21: 447-58.

14. Silva NF, Sichieri R, Pereira RA, Silva RM, Ferreira MG. Reproducibility, relative validity and calibration of a food frequency questionnaire for adults. Cadernos de saude publica. 2013;29:1783-94.
15. Zhuang M, Yuan Z, Lin L, Hu B, Wang X, Yang Y, Chen X, Jin L, Lu M, Ye W. Reproducibility and relative validity of a food frequency questionnaire developed for adults in Taizhou, China. PloS one. 2012;7:e48341.

16. Zang J, Luo B, Chang S, Jin S, Shan C, Ma L, Zhu Z, Guo C, Zou S, Jia X, Wu F. Validity and reliability of a food frequency questionnaire for assessing dietary intake among Shanghai residents. Nutr J. 2019;18:30.

17. Marshall SJ, Livingstone KM, Celis-Morales C, Forster H, Fallaize R, O'Donovan CB, Woolhead C, Marsaux CF, Macready AL, Navas-Carretero S, et al. Reproducibility of the online Food4Me food-frequency questionnaire for estimating dietary intakes across Europe. J Nutr. 2016;146:1068-75.

18. Tijerina A, Tur JA. Development and validation of a Semiquantitative food frequency questionnaire to assess dietary intake in 40-65-year-old Mexican women. Ann Nutr Metabol. 2020:76:73-82.

19. El Kinany K, Garcia-Larsen V, Khalis M, Deoula MMS, Benslimane A, Ibrahim A, Benjelloun MC, El Rhazi K. Adaptation and validation of a food frequency questionnaire (FFQ) to assess dietary intake in Moroccan adults. Nutr J. 2018;17:61.

20. Sam CHY, Skidmore P, Skeaff S, Wall C, Bradbury KE, Parackal S. Relative validity and reproducibility of a short FoodFrequency questionnaire to assess nutrient Intakesof New Zealand adults. Nutrients. 2020;12:619.

21. Tsubono Y, Kobayashi M, Sasaki S, Tsugane S, JPHC. Validity and reproducibility of a self-administered food frequency questionnaire used in the baseline survey of the JPHC study cohort I. J Epidemiol. 2003;13:S12533.

22. Xing X, Burr JA, Brasure JR, Neugut Al, Marshall JR. Reproducibility of nutrient intake in a food frequency questionnaire used in a general population. Nutr Cancer. 1996;25:259-68.

23. Jackson MD, Motswagole BS, Kwape LD, Kobue-Lekalake Rl, Rakgantswana TB, Mongwaketse T, Mokotedi M, Jackson-Malete J. Validation and reproducibility of an FFQ for use among adults in Botswana. Public Health Nutr. 2013;16:1995-2004

24. Ahn Y, Kwon E, Shim JE, Park MK, Joo Y, Kimm K, Park C, Kim DH. Validation and reproducibility of food frequency questionnaire for Korean genome epidemiologic study. Eur J Clin Nutr. 2007;61:1435-41.

25. Hong TK, Dibley MJ, Sibbritt D. Validity and reliability of an FFQ for use with adolescents in Ho Chi Minh City, Vietnam. Public Health Nutr. 2010;13:36875

26. Bae YJ, Choi HY, Sung MK, Kim MK, Choi MK. Validity and reproducibility of a food frequency questionnaire to assess dietary nutrients for prevention and management of metabolic syndrome in Korea. Nutr Res Pract. 2010;4: 121-7.

27. Barrat E, Aubineau N, Maillot M, Derbord E, Barthes P, Lescuyer JF, Boisseau $\mathrm{N}$, Peltier SL. Repeatability and relative validity of a quantitative foodfrequency questionnaire among French adults. Food Nutr Res. 2012;56: 18472

28. Bjerregaard AA, Tetens I, Olsen SF, Halldorsson TI. Reproducibility of a webbased FFQ for 13- to 15-year-old Danish adolescents. J Nutrit Sci. 2016;5:e5.

29. Bohlscheid-Thomas S, Hoting I, Boeing H, Wahrendorf J. Reproducibility and relative validity of energy and macronutrient intake of a food frequency questionnaire developed for the German part of the EPIC project. European Prospective Investigation into Cancer and Nutrition. Int J Epidemiol. 1997; 26(Suppl 1):S71-81.

30. Boucher B, Cotterchio M, Kreiger N, Nadalin V, Block T, Block G. Validity and reliability of the Block98 food-frequency questionnaire in a sample of Canadian women. Public Health Nutr. 2006:9:84-93.

31. Zhang CX, Ho SC. Validity and reproducibility of a food frequency questionnaire among Chinese women in Guangdong province. Asia Pac J Clin Nutr. 2009;18:240-50,

32. Cantin J, Latour E, Ferland-Verry R, Morales Salgado S, Lambert J, Faraj M, Nigam A. Validity and reproducibility of a food frequency questionnaire focused on the Mediterranean diet for the Quebec population. Nutr Metab Cardiovasc Dis. 2016;26:154-61.

33. Cardoso MA. Reproducibility and validity of a food frequency questionnaire among women of Japanese ancestry living in Brazil; 2001.

34. Collins CE, Boggess MM, Watson JF, Guest M, Duncanson K, Pezdirc K, Rollo M, Hutchesson MJ, Burrows TL. Reproducibility and comparative validity of a food frequency questionnaire for Australian adults. Clin Nutr. 2014:33:906-14.

35. Dehghan M, del Cerro S, Zhang X, Cuneo JM, Linetzky B, Diaz R, Merchant AT. Validation of a semi-quantitative food frequency questionnaire for Argentinean adults. PLoS One. 2012;7:e37958. 
36. Dehghan M, Ilow R, Zatonska K, Szuba A, Zhang X, Mente A, Regulska-llow B. Development, reproducibility and validity of the food frequency questionnaire in the Poland arm of the prospective urban and rural epidemiological (PURE) study. J Hum Nutr Diet. 2012;25:225-32.

37. Deschamps V, de Lauzon-Guillain B, Lafay L, Borys JM, Charles MA, Romon M. Reproducibility and relative validity of a food-frequency questionnaire among French adults and adolescents. Eur J Clin Nutr. 2009;63:282-91.

38. Doustmohammadian A, Amini M. Validity and reliability of a dish-based semi-quantitative food frequency questionnaire for assessment of energy and nutrient intake among Iranian adults, vol. 13; 2020. p. 95.

39. Dumartheray EW, Krieg MA, Cornuz J, Whittamore DR, Lovell DP, Burckhardt P, Lanham-New SA. Validation and reproducibility of a semi-quantitative food frequency questionnaire for use in elderly Swiss women. J Hum Nutr Diet. 2006;19:321-30

40. Egami I, Wakai K, Kato K, Lin Y, Kawamura T, Tamakoshi A, Aoki R, Kojima M, Nakayama T, Wada M, Ohno Y. A simple food frequency questionnaire for Japanese diet--part II. Reproducibility and validity for nutrient intakes. J Epidemiol. 1999;9:227-34.

41. El Kinany K, Garcia-Larsen V. Adaptation and validation of a food frequency questionnaire (FFQ) to assess dietary intake in Moroccan adults, vol. 17; 2018. p. 61.

42. Elorriaga $N$, Irazola VE, Defagó MD, Britz M, Martínez-Oakley SP, Witriw AM, Rubinstein AL. Validation of a self-administered FFQ in adults in Argentina, Chile and Uruguay. Public Health Nutr. 2015;18:59-67.

43. Engle A, Lynn LL, Koury K, Boyar AP. Reproducibility and comparability of a computerized, self-administered food frequency questionnaire. Nutr J. 1990; 13:281-92.

44. Fallaize $\mathrm{R}$, Forster $\mathrm{H}$. Online dietary intake estimation: reproducibility and validity of the Food4Me food frequency questionnaire against a 4-day weighed food record. J Med Internet Res. 2014;16:e190.

45. Fernández-Ballart JD, Piñol JL, Zazpe I, Corella D, Carrasco P, Toledo E, PerezBauer M, Martínez-González MA, Salas-Salvadó J, Martín-Moreno JM. Relative validity of a semi-quantitative food-frequency questionnaire in an elderly Mediterranean population of Spain. Br J Nutr. 2010;103:1808-16.

46. Field AE, Peterson KE, Gortmaker SL, Cheung L, Rockett H, Fox MK, Colditz GA. Reproducibility and validity of a food frequency questionnaire among fourth to seventh grade inner-city school children: implications of age and day-to-day variation in dietary intake. Public Health Nutr. 1999;2:293-300.

47. Filippi AR, Amodio E, Napoli G, Breda J, Bianco A, Jemni M, Censi L, Mammina C, Tabacchi G. The web-based ASSO-food frequency questionnaire for adolescents: relative and absolute reproducibility assessment. Clin Nutr Res. 2014;13:119.

48. Flagg EW, Coates RJ, Calle EE, Potischman N, Thun MJ. Validation of the American Cancer Society Cancer Prevention Study II Nutrition Survey Cohort Food Frequency Questionnaire. Epidemiology. 2000;11:462-8.

49. Friis S, Kruger Kjaer S, Stripp C, Overvad K. Reproducibility and relative validity of a self-administered semiquantitative food frequency questionnaire applied to younger women. J Clin Epidemiol. 1997;50:303-11.

50. Gilsing A, Mayhew AJ, Payette H, Shatenstein B, Kirkpatrick SI, Amog K, Wolfson C, Kirkland S, Griffith LE, Raina P. Validity and reliability of a short diet questionnaire to estimate dietary intake in older adults in a subsample of the Canadian longitudinal study on aging. Nutrients. 2018;10:1522.

51. Gnardellis C, Trichopoulou A, Katsouyanni K, Polychronopoulos E, Rimm EB, Trichopoulos D. Reproducibility and validity of an extensive semiquantitative food frequency questionnaire among Greek school teachers. Epidemiology. 1995;6:74-7.

52. Goulet J, Nadeau G, Lapointe A, Lamarche B, Lemieux S. Validity and reproducibility of an interviewer-administered food frequency questionnaire for healthy French-Canadian men and women. Nutr J. 2004;3:13.

53. Hernández-Avila M, Romieu I, Parra S, Hernández-Avila J, Madrigal H, Willett W. Validity and reproducibility of a food frequency questionnaire to assess dietary intake of women living in Mexico City. Salud publica de Mexico. 1998:40:133-40.

54. Ibiebele TI, Parekh S, Mallitt KA, Hughes MC, O'Rourke PK, Webb PM. Australian ovarian Cancer study G, the Australian Cancer S: reproducibility of food and nutrient intake estimates using a semi-quantitative FFQ in Australian adults. Public Health Nutr. 2009;12:2359-65.

55. Imaeda N, Goto C, Tokudome Y, Hirose K, Tajima K, Tokudome S. Reproducibility of a short food frequency questionnaire for Japanese general population. J Epidemiol. 2007;17:100-7.

56. Iqbal R, Ajayan K, Bharathi AV, Zhang X, Islam S, Soman CR, Merchant AT. Refinement and validation of an FFQ developed to estimate macro- and micronutrient intakes in a south Indian population. Public Health Nutr. 2009;12:12-8.
57. Ishihara J, Sobue T, Yamamoto S, Yoshimi I, Sasaki S, Kobayashi M, Takahashi T, litoi Y, Akabane M, Tsugane S. Validity and reproducibility of a selfadministered food frequency questionnaire in the JPHC study cohort II: study design, participant profile and results in comparison with cohort I. J Epidemiol. 2003;13:S134-47.

58. Ishihara J, Iwasaki M, Kunieda CM, Hamada GS, Tsugane S. Food frequency questionnaire is a valid tool in the nutritional assessment of Brazilian women of diverse ethnicity. Asia Pac J Clin Nutr. 2009;18:76-80.

59. Jackson M, Walker S, Cade J, Forrester T, Cruickshank JK, Wilks R. Reproducibility and validity of a quantitative food-frequency questionnaire among Jamaicans of African origin. Public Health Nutr. 2001;4:971-80.

60. Jackson MD, Walker SP, Younger NM, Bennett FI. Use of a food frequency questionnaire to assess diets of Jamaican adults: validation and correlation with biomarkers. Nutr J. 2011;10:28.

61. Esmaillzadeh A, Omidvar N, Abtahi M, Dadkhah-Piraghaj M, Nikooyeh B, Neyestani TR, Jain MG, Rohan TE, Soskolne CL, Kreiger N. Calibration of the dietary questionnaire for the Canadian study of diet, lifestyle and health cohort. BMC Res Notes. 2003;6:79-86.

62. Johansson I, Hallmans G, Wikman A, Biessy C, Riboli E, Kaaks R. Validation and calibration of food-frequency questionnaire measurements in the northern Sweden health and disease cohort. Public Health Nutr. 2002;5:487-96.

63. Johansson L, Solvoll K, Opdahl S, Bjørneboe GE, Drevon CA. Response rates with different distribution methods and reward, and reproducibility of a quantitative food frequency questionnaire. Eur J Clin Nutr. 1997;51:346-53.

64. Teixeira JA, Baggio ML, Giuliano AR, Fisberg RM, Marchioni DM. Performance of the quantitative food frequency questionnaire used in the Brazilian center of the prospective study natural history of human papillomavirus infection in men: the HIM study. J Am Diet Assoc. 2011;111:1045-51.

65. Katsouyanni K, Rimm EB, Gnardellis C, Trichopoulos D, Polychronopoulos E, Trichopoulou A. Reproducibility and relative validity of an extensive semiquantitative food frequency questionnaire using dietary records and biochemical markers among Greek schoolteachers. Int J Epidemiol. 1997; 26(Suppl 1):S118-27.

66. Kesse-Guyot E, Castetbon K, Touvier M, Hercberg S, Galan P. Relative validity and reproducibility of a food frequency questionnaire designed for French adults. Ann Nutr Metabol. 2010;57:153-62.

67. Kim DW, Song S, Lee JE, Oh K, Shim J, Kweon S, Paik HY, Joung H. Reproducibility and validity of an FFQ developed for the Korea National Health and nutrition examination survey (KNHANES). Public Health Nutr. 2015;18:1369-77.

68. Kristal AR, Kolar AS, Fisher JL, Plascak JJ, Stumbo PJ, Weiss R, Paskett ED. Evaluation of web-based, self-administered, graphical food frequency questionnaire. J Acad Nutr Diet. 2014;114:613-21.

69. Labonté M, Cyr A, Baril-Gravel L, Royer MM, Lamarche B. Validity and reproducibility of a web-based, self-administered food frequency questionnaire. Eur J Clin Nutr. 2012;66:166-73.

70. Lazarus R, Wilson A, Gliksman M, Aiken J. Repeatability of nutrient intakes estimated by a semiquantitative food frequency questionnaire in elderly subjects. Ann Epedimiol. 1995:5:65-8.

71. Lee Y, Park K. Reproducibility and validity of a semi-quantitative FFQ for trace elements. Br J Nutr. 2016;116:864-73.

72. Lee MS, Pan WH, Liu KL, Yu MS. Reproducibility and validity of a Chinese food frequency questionnaire used in Taiwan. Asia Pac J Clin Nutr. 2006;15:161-9.

73. Leon Guerrero RT, Chong M, Novotny R, Wilkens LR, Badowski G, BlasLaguana M, Murphy S. Relative validity and reliability of a quantitative food frequency questionnaire for adults in Guam. Food Nutr Res. 2015; 59:26276.

74. Longnecker MP, Lissner L, Holden JM, Flack VF, Taylor PR, Stampfer MJ, Willett WC. The reproducibility and validity of a self-administered semiquantitative food frequency questionnaire in subjects from South Dakota and Wyoming. Epidemiology. 1993:4:356-65.

75. Lyu LC, Lin CF, Chang FH, Chen HF, Lo CC, Ho HF. Meal distribution, relative validity and reproducibility of a meal-based food frequency questionnaire in Taiwan. Asia Pac J Clin Nutr. 2007;16:766-76.

76. Macedo-Ojeda G, Vizmanos-Lamotte B, Márquez-Sandoval YF, RodríguezRocha NP, López-Uriarte PJ, Fernández-Ballart JD. Validation of a semiquantitative food frequency questionnaire to assess food groups and nutrient intake. Nutricion Hospitalaria. 2013;28:2212-20.

77. Maclntyre UE, Venter CS, Vorster HH. A culture-sensitive quantitative food frequency questionnaire used in an African population: 1. Development and reproducibility. Public Health Nutr. 2001;4:53-62. 
78. Malekshah AF, Kimiagar M, Saadatian-Elahi M, Pourshams A, Nouraie M, Goglani G, Hoshiarrad A, Sadatsafavi M, Golestan B, Yoonesi A, et al. Validity and reliability of a new food frequency questionnaire compared to $24 \mathrm{~h}$ recalls and biochemical measurements: pilot phase of Golestan cohort study of esophageal cancer. Eur J Clin Nutr. 2006;60:971-7.

79. Männistö S, Virtanen M, Mikkonen T, Pietinen P. Reproducibility and validity of a food frequency questionnaire in a case-control study on breast cancer. J Clin Epidemiol. 1996:49:401-9.

80. Overby NC, Johannesen E, Jensen G, Skjaevesland AK, Haugen M. Test-retest reliability and validity of a web-based food-frequency questionnaire for adolescents aged 13-14 to be used in the Norwegian mother and child cohort study (MoBa). Food Nutr Res. 2014;58:23956.

81. Marchioni DM, Voci SM, Lima FE, Fisberg RM, Slater B. Reproducibility of a food frequency questionnaire for adolescents. Cadernos de saude publica. 2007:23:2187-96.

82. Marques-Vidal P, Ross A, Wynn E, Rezzi S, Paccaud F, Decarli B. Reproducibility and relative validity of a food-frequency questionnaire for French-speaking Swiss adults. Food Nutr Res. 2011;55:5905.

83. Martinez MF, Philippi ST, Estima C, Leal G. Validity and reproducibility of a food frequency questionnaire to assess food group intake in adolescents. Cadernos de saude publica. 2013:29:1795-804

84. Martin-Moreno JM, Boyle P, Gorgojo L, Maisonneuve P, FernandezRodriguez JC, Salvini S, Willett WC. Development and validation of a food frequency questionnaire in Spain. Int J Epidemiol. 1993;22:512-9.

85. Maruyama K, Kokubo Y, Yamanaka T, Watanabe M, Iso H, Okamura T, Miyamoto $Y$. The reasonable reliability of a self-administered food frequency questionnaire for an urban, Japanese, middle-aged population: the Suita study. Nutr Res. 2015;35:14-22.

86. Marventano S, Mistretta A, Platania A, Galvano F, Grosso G. Reliability and relative validity of a food frequency questionnaire for Italian adults living in Sicily, southern Italy. Int J Food Sci Nutr. 2016;67:857-64.

87. McPherson RS, Kohl HW 3rd, Garcia G, Nichaman MZ, Hanis CL. Foodfrequency questionnaire validation among Mexican-Americans: Starr County, Texas. Ann Epedimiol. 1995;5:378-85.

88. Messerer M, Johansson SE, Wolk A. The validity of questionnaire-based micronutrient intake estimates is increased by including dietary supplement use in Swedish men. J Nutr. 2004;134:1800-5.

89. Mirmiran P, Esfahani FH, Mehrabi Y, Hedayati M, Azizi F. Reliability and relative validity of an FFQ for nutrients in the Tehran lipid and glucose study. Public Health Nutr. 2010;13:654-62.

90. Morris MC, Tangney CC, Bienias JL, Evans DA, Wilson RS. Validity and reproducibility of a food frequency questionnaire by cognition in an older biracial sample. Am J Epidemiol. 2003;158:1213-7.

91. Ocké MC, Bueno-de-Mesquita HB, Pols MA, Smit HA, van Staveren WA, Kromhout D. The Dutch EPIC food frequency questionnaire. II. Relative validity and reproducibility for nutrients. Int J Epidemiol. 1997;26(Suppl 1): S49-58.

92. Ogawa K, Tsubono Y, Nishino Y, Watanabe Y, Ohkubo T, Watanabe T, Nakatsuka H, Takahashi N, Kawamura M, Tsuji I, Hisamichi S. Validation of a food-frequency questionnaire for cohort studies in rural Japan. Public Health Nutr. 2003:6:147-57.

93. Palacios C, Trak MA, Betancourt J, Joshipura K, Tucker KL. Validation and reproducibility of a semi-quantitative FFQ as a measure of dietary intake in adults from Puerto Rico. Public Health Nutr. 2015;18:2550-8.

94. Park MK, Noh HY, Song NY, Paik HY, Park S, Joung H, Song WO, Kim J. Validity and reliability of a dish-based, semi-quantitative food frequency questionnaire for Korean diet and cancer research. Asian Pac J Cancer Prev. 2012;13:545-52

95. Preston AM, Palacios C, Rodríguez CA, Vélez-Rodríguez RM. Validation and reproducibility of a semi-quantitative food frequency questionnaire for use in Puerto Rican children. P R Health Sci J. 2011;30:58-64.

96. Riboli E, Toniolo P, Kaaks R, Shore RE, Casagrande C, Pasternack BS. Reproducibility of a food frequency questionnaire used in the New York University Women's health study: effect of self-selection by study subjects. Eur J Clin Nutr. 1997;51:437-42.

97. Rifas-Shiman SL, Willett WC, Lobb R, Kotch J, Dart C, Gillman MW. PrimeScreen, a brief dietary screening tool: reproducibility and comparability with both a longer food frequency questionnaire and biomarkers. Public Health Nutr. 2001;4:249-54.

98. Rimm EB, Giovannucci EL, Stampfer MJ, Colditz GA, Litin LB, Willett WC Reproducibility and validity of an expanded self-administered semiquantitative food frequency questionnaire among male health professionals. Am J Epidemiol. 1992;135:1114-26 discussion 1127-1136.

99. Rockett HR, Wolf AM, Colditz GA. Development and reproducibility of a food frequency questionnaire to assess diets of older children and adolescents. J Am Diet Assoc. 1995;95:336-40.

100. Rodriguez CA, Smith ER, Villamor E, Zavaleta N, Respicio-Torres G, Contreras C, Perea S, Jimenez J, Tintaya K, Lecca L, et al. Development and validation of a food frequency questionnaire to estimate intake among children and adolescents in urban Peru. Nutrients. 2017;9:1121.

101. Salvesen L, Hillesund ER, Vik FN, Brantsæter AL. Reproducibility and relative validity of a newly developed web-based food-frequency questionnaire for assessment of preconception diet. BMC Nutr. 2019;5:47.

102. Sam CH, Skeaff S, Skidmore PM. A comprehensive FFQ developed for use in New Zealand adults: reliability and validity for nutrient intakes. Public Health Nutr. 2014;17:287-96.

103. Sasaki S, Ishihara J, Tsugane S. Reproducibility of a self-administered food frequency questionnaire used in the 5-year follow-up survey of the JPHC study cohort I to assess food and nutrient intake. J Epidemiol. 2003;13:S115-24.

104. Sanjeevi N, Freeland-Graves J, George GC. Relative validity and reliability of a 1-week, semiquantitative food frequency questionnaire for women participating in the supplemental nutrition assistance program. J Acad Nutr Diet. 2017;117:1972-1982.e1972.

105. Schröder H, Covas MI, Marrugat J, Vila J, Pena A, Alcántara M, Masiá R. Use of a three-day estimated food record, a 72-hour recall and a food-frequency questionnaire for dietary assessment in a Mediterranean Spanish population. Clin Nutr. 2001;20:429-37.

106. Selem SS, Carvalho AM, Verly-Junior E, Carlos JV, Teixeira JA, Marchioni DM, Fisberg RM. Validity and reproducibility of a food frequency questionnaire for adults of São Paulo, Brazil. Rev Braz Epidemiol. 2014;17:852-9.

107. Shimizu H, Ohwaki A, Kurisu Y, Takatsuka N, Ido M, Kawakami N, Nagata C, Inaba S. Validity and reproducibility of a quantitative food frequency questionnaire for a cohort study in Japan. Jpn J Clin Oncol. 1999;29:38-44.

108. Shu XO, Yang G, Jin F, Liu D, Kushi L, Wen W, Gao YT, Zheng W. Validity and reproducibility of the food frequency questionnaire used in the Shanghai Women's health study. Eur J Clin Nutr. 2004;58:17-23.

109. Silva-Jaramillo KM, Neutzling MB, Drehmer M. FFQ for the adult population of the capital of Ecuador (FFQ-Quito): development, reliability and validity. Public Health Nutr. 2015;18:2540-9.

110. Sudha V, Radhika G, Sathya RM, Ganesan A, Mohan V. Reproducibility and validity of an interviewer-administered semi-quantitative food frequency questionnaire to assess dietary intake of urban adults in southern India. Int J Food Sci Nutr. 2006:57:481-93.

111. Tang Y, Liu Y, Xu L, Jia Y, Shan D, Li W, Pan X, Kang D, Huang C, Li X, et al. Validity and reproducibility of a revised semi-quantitative food frequency questionnaire (SQFFQ) for women of age-group 12-44 years in Chengdu. J Health Popul Nutr. 2015;33:50-9.

112. Tollosa DN, Van Camp J, Huybrechts I, Huybregts L, Van Loco J, De Smet S, Sterck E, Rabâi C, Van Hecke T, Vanhaecke L, et al. Validity and reproducibility of a food frequency questionnaire for dietary factors related to colorectal Cancer. Int J Environ Res Public Health. 2017;9:1257.

113. Tavani A, Negri E, Ferraroni M, D'Avanzo B, Decarli A, Giacosa A, La Vecchia C, Nanni O, Parpinel MT, Salvini S, et al. Influence of some covariates on the reproducibility of an Italian semi-quantitative food frequency questionnaire. Eur J Cancer Prev. 1995;4:319-27.

114. Villegas R, Yang G, Liu D, Xiang YB, Cai H, Zheng W, Shu XO. Validity and reproducibility of the food-frequency questionnaire used in the Shanghai men's health study. Br J Nutr. 2007;97:993-1000.

115. Watanabe M, Yamaoka K, Yokotsuka M, Adachi M, Tango T. Validity and reproducibility of the FFQ (FFQW82) for dietary assessment in female adolescents. Public Health Nutr. 2011;14:297-305.

116. Watson JF, Collins CE, Sibbritt DW, Dibley MJ, Garg ML. Reproducibility and comparative validity of a food frequency questionnaire for Australian children and adolescents. Int J Behav Nutr Phys Act. 2009;6:62.

117. Whitton C, Ho JCY, Tay Z, Rebello SA, Lu Y, Ong CN, van Dam RM. Relative validity and reproducibility of a food frequency questionnaire for assessing dietary intakes in a multi-ethnic Asian population using 24-h dietary recalls and biomarkers. Nutrients. 2017;9:1059.

118. Willett WC, Sampson L, Stampfer MJ, Rosner B, Bain C, Witschi J, Hennekens $\mathrm{CH}$, Speizer FE. Reproducibility and validity of a semiquantitative food frequency questionnaire. Am J Epidemiol. 1985;122:51-65. 
119. Vereecken CA, De Bourdeaudhuij I, Maes L. The HELENA online food frequency questionnaire: reproducibility and comparison with four 24-h recalls in Belgian-Flemish adolescents. Eur J Clin Nutr. 2010;64:541-8.

120. Xia W, Sun C, Zhang L, Zhang X, Wang J, Wang H, Wu L. Reproducibility and relative validity of a food frequency questionnaire developed for female adolescents in Suihua, North Carolina. J Nutr Gerontol Geriatr. 2011;6:e19656.

121. Zaragoza-Martí A, Ferrer-Cascales R, Hurtado-Sánchez JA, Laguna-Pérez A, Cabañero-Martínez MJ. Cross-cultural adaptation, validity, and reproducibility of the Mediterranean Islands study food frequency questionnaire in the elderly population living in the Spanish Mediterranean. Nutrients. 2018;10:1206.

122. Xu L, Dibley MJ, D'Este C. Reliability and validity of a food-frequency questionnaire for Chinese postmenopausal women. Public Health Nutr. 2004;7:91-8.

123. Yum J, Lee S. Development and evaluation of a dish-based semiquantitative food frequency questionnaire for Korean adolescents. Nutr Res Pract. 2016; 10:433-41.

124. Zhang M, Binns CW, Lee AH. A quantitative food frequency questionnaire for women in Southeast China: development and reproducibility. Nutr Dietet. 2005;17:29-35.

125. Ye Q, Hong $X$, Wang $Z$, Yang $H$, Chen $X$, Zhou $H$, Wang $C$, Lai $Y$, Sun L, Xu F. Reproducibility and validity of an FFQ developed for adults in Nanjing, China. Br J Nutr. 2016;115:887-94.

126. Yuan C, Spiegelman D, Rimm EB, Rosner BA, Stampfer MJ, Barnett JB, Chavarro JE, Subar AF, Sampson LK, Willett WC. Validity of a dietary questionnaire assessed by comparison with multiple weighed dietary records or 24-hour recalls. Am J Epidemiol. 2017;185:570-84.

127. Tsubono Y, Ogawa K, Watanabe Y, Nishino Y, Tsuji I, Watanabe T, Nakatsuka H, Takahashi N, Kawamura M, Hisamichi S. Food frequency questionnaire and a screening test. Nutr Cancer. 2001;39:78-84.

128. Shai I, Rosner BA, Shahar DR, Vardi H, Azrad AB, Kanfi A, Schwarzfuchs D, Fraser D, Study D. Dietary evaluation and attenuation of relative risk: multiple comparisons between blood and urinary biomarkers, food frequency, and 24-hour recall questionnaires: the DEARR study. J Nutr. 2005; 135:573-9.

129. Fornés NS, Stringhini ML, Elias BM. Reproducibility and validity of a foodfrequency questionnaire for use among low-income Brazilian workers. Public Health Nutr. 2003:6:821-7.

130. Nouri M, Ghazizahedi S, Mohajeri SA. Relative validity and reproducibility of a semi-quantitative food frequency questionnaire among urban Iranians. Int J Health Life Sci. 2017;3(1):60-70.

131. McKeown NM, Day NE, Welch AA, Runswick SA, Luben RN, Mulligan AA, McTaggart A, Bingham SA. Use of biological markers to validate selfreported dietary intake in a random sample of the European prospective investigation into Cancer United Kingdom Norfolk cohort. Am J Clin Nutr. 2001;74:188-96.

132. Munger RG, Folsom AR, Kushi LH, Kaye SA, Sellers TA. Dietary assessment of older lowa women with a food frequency questionnaire: nutrient intake reproducibility, and comparison with 24 -hour dietary recall interviews. Am J Epidemiol. 1992;136:192-200

133. Zapataa ME, Buffarinib R, Lingiardia N, Gonçalves-Soaresb AL. Reproducibility and relative validity of a semi-quantitative food-frequency questionnaire in an adult population of Rosario, Argentina; 2015.

134. Smith W, Mitchell P, Reay EM, Webb K, Harvey PW. Validity and reproducibility of a self-administered food frequency questionnaire in older people. Aust N Z J Public Health. 1998;22:456-63.

135. WalterWillett. Nutritional epidemiology. New York: Oxford University Press; 1998.

136. Mahajan R, Malik M, Bharathi AV, Lakshmi PV, Patro BK, Rana SK, Kumar R. Reproducibility and validity of a quantitative food frequency questionnaire in an urban and rural area of northern India. Nat Med JIndia. 2013;26:26672.

137. Fallaize R, Forster H, Macready AL, Walsh MC, Mathers JC, Brennan L, Gibney ER, Gibney MJ, Lovegrove JA. Online dietary intake estimation: reproducibility and validity of the Food4Me food frequency questionnaire against a 4-day weighed food record. J Med Internet Res. 2014;16:e190.

138. Chen Q, Marques-Vidal P. Trends in food availability in Portugal in 19662003: comparison with other Mediterranean countries. Eur J Nutr. 2007:46: 418-27
139. Bobak M, Skodova Z, Pisa Z, Poledne R, Marmot M. Political changes and trends in cardiovascular risk factors in the Czech Republic, 1985-92. J Epidemiol Community Health. 1997;51:272-7.

\section{Publisher's Note}

Springer Nature remains neutral with regard to jurisdictional claims in published maps and institutional affiliations.
Ready to submit your research? Choose BMC and benefit from:

- fast, convenient online submission

- thorough peer review by experienced researchers in your field

- rapid publication on acceptance

- support for research data, including large and complex data types

- gold Open Access which fosters wider collaboration and increased citations

- maximum visibility for your research: over $100 \mathrm{M}$ website views per year

At $\mathrm{BMC}$, research is always in progress.

Learn more biomedcentral.com/submissions 